\title{
Review \\ A Literature Review of Emerging Research Needs for Micromobility-Integration through a Life Cycle Thinking Approach
}

\author{
Daniel L. Marques * (D) and Margarida C. Coelho $\mathbb{C}$
}

Citation: Marques, D.L.; Coelho, M.C. A Literature Review of Emerging Research Needs for MicromobilityIntegration through a Life Cycle Thinking Approach. Future Transp. 2022, 2, 135-164. https://doi.org/ 10.3390/futuretransp2010008

Academic Editors: Armando Cartenì and Antonio Comi

Received: 18 November 2021

Accepted: 30 January 2022

Published: 4 February 2022

Publisher's Note: MDPI stays neutral with regard to jurisdictional claims in published maps and institutional affiliations.

Copyright: (C) 2022 by the authors. Licensee MDPI, Basel, Switzerland. This article is an open access article distributed under the terms and conditions of the Creative Commons Attribution (CC BY) license (https:// creativecommons.org/licenses/by/ $4.0 /$ )
Centre for Mechanical Technology and Automation (TEMA), Department of Mechanical Engineering, University of Aveiro, Campus Universitário de Santiago, 3810-193 Aveiro, Portugal; margarida.coelho@ua.pt

* Correspondence: danielmarques11@ua.pt

\begin{abstract}
Micromobility is an increasingly attractive option, particularly over short distances. Walking, biking, and other modes of transport, such as e-scooters, are gaining popularity. Furthermore, a trend is emerging to introduce appealing items onto the market that incorporate new / more sustainable materials to improve wellbeing. Significant research questions concern the understanding of emerging research needs and the environmental, social, and economic effects of sustainability in the micromobility transport system, specifically because of developing and implementing new products, boosting the safety and comfort of ergonomic personal mobility devices (PMDs), and assuring security and privacy while digitalization arises. Such research topics can raise policymakers and the public's awareness while providing impactful information for decision-makers. This paper provides a literature review of the most recent research on micromobility-related topics. It uses scientific databases, a keywords list, and defined inclusion criteria to select data, analyze content, and perform a bibliometric analysis. The findings highlight the significance of using Life Cycle Assessment (LCA) tools together with other methodologies to aid in the evaluation of urban complexity. Finally, using a life cycle thinking (LCT) approach, we propose a framework for comprehensively integrating identified research needs.
\end{abstract}

Keywords: micromobility; personal mobility devices; sustainable mobility; mobility trends; policymakers; research needs; life cycle thinking; future mobility; literature review

\section{Introduction}

Many cities worldwide have been dealing with the adverse externalities of car travel. Furthermore, society understands that driving a private car negatively impacts one's quality of life in terms of air quality, emissions, traffic, and psychological wellbeing [1]. As a result, the proliferation of micromobility modes of personal transport and greater electrical and digital connectivity promotes behavioral changes. The way people travel in urban areas is rapidly changing as this concept is quickly adopted and promoted as a means of achieving a more sustainable transport system [2-4]. Micromobility has emerged in the urban context as a potential answer to the first/last mile problem, and active modes (e-scooters, cycling, or any mode requiring physical effort) have taken over their space in the urban transport sector, mostly due to new mobility options, systems/services, and patterns provided by associated suppliers [5].

Chiefly for bicycles, until the late 1990s, fewer than ten cities worldwide had shared mobility systems. In 2019, there were over 2900, a number that stabilized around that value until August 2021 [6-8]. At a significantly faster pace, e-scooters have entered circulation in over 100 cities since 2017 [9], particularly through shared mobility services or adoption as a personal mobility device (PMD). Both support traffic volume and congestion reduction, as these can help cities ease harmful emissions [3-5]. 
Hence, such new urban mobility solutions have been often labeled as sustainable following the EU's policy focus in supporting Research and Development (R\&D) to reduce $\mathrm{CO}_{2}$ emissions and transport's negative externalities [10]. Furthermore, three goals are identified as crucial for micromobility to achieve macro impacts on sustainability. Firstly, to reduce greenhouse gases emissions (GHG) by mode shifting from automobiles. Secondly, to achieve reliability, equity, and affordability through sustainable business models. Lastly, to reduce existing mobility barriers and enhance the travel experience. Research further advocates that the full potential of sustainable micromobility is achievable if a flexible and iterative life cycle approach is considered [11].

However, the modal shift must account for the reduction of traveled distances by other vehicles such as buses and streetcars. If it only results in empty pollutant vehicles dwelling in a city, then the impacts of micromobility could reflect on more offer than demand and potentially harm its environmental benefits [12]. At once, reducing polluting particles by replacing motor vehicles is not the only crucial metric. From an environmental and health angle, users' exposure when traveling through highly polluted and noisy cities should be equally considered [13]. A user can opt for an e-bicycle or a traditional, more intense, and healthier one. Both are viable, healthy alternatives, however, the rates of required physical effort differ depending on the chosen PMD. Such choice and the coexistence with polluting modes will shape the users' patterns and traveled distances. As a result, the health benefits, users' exposure, and sustainability advances are yet to be measured. For instance, whether and over what distances should PMDs replace motorized vehicles [14,15].

Moreover, the actual impacts on energy demand and GHG emissions over the entire life cycle are frequently insufficient for the first goal [16]. Life Cycle Assessment (LCA) studies on micromobility modes do not include the impacts related to pavements and infrastructure [17]. Furthermore, safety and health effects, including pedestrian and cyclist deaths or injuries, as well as equity, are regarded as critical issues in transport.

Such critical issues raise important socioeconomic challenges and research questions with impact on the second and third goals. The interaction of last/first mile modes with urban transport systems, for instance, requires policy and infrastructural changes. Additionally, there are unforeseen outcomes such as careless riding, cluttering, and vandalism, while vehicles, service providers, and users coexist in the mobility sector, all being vulnerable to attacks to their security from malicious or dishonest outsiders. This stresses the need for a holistic approach that embraces safety, security, injury, or crash prediction-related studies that enhance the collaborative interoperability between business/economic, engineering, political, and social sectors $[18,19]$.

Likewise, bike-sharing systems illustrate a modern travel mode adapted in many countries and can be tailored to individual needs. The concept of Mobility as a Service (MaaS) might help to implement such systems through techniques such as mobile data mining $[20,21]$. Thus, more and more data will be generated, contributing to reducing the data scarcity, which will require new tools and training [22]. Such collaborative technological disruption and digitalization is a challenge, which will demand supportive legislation for multimodal shared mobility - for instance, by enabling data sharing about infrastructure provision and innovative technological applications between service providers and governments [23]. It will also be crucial to regulate the vehicles' classes and use, and primarily to enforce the regulations. Specifically, to create a more uniform legislation pack that can serve urban planning globally $[24,25]$. Thus, developing a smart and active context for micromobility through sustainable businesses and enhancing travel experience is dependent on embracing new challenges under an aggregating perspective.

To the best of the authors' knowledge, papers aiming for a literature review on recent progress in micromobility with a critical view on its potential, applicability, and future research needs are unknown. $\mathrm{O}^{\prime}$ Hern et al. [25] conducted a scientometric review, emphasizing that powered micromobility is growing. Their findings highlight the importance of road safety, use, and legislation and the potential benefits of micromobility. However, they recognize many unknowns that require academic research [25]. Similarly, Abduljab- 
bar et al. [26] investigate micromobility in the context of improving cities' sustainability. Their literature review categorizes the topic into four themes: benefits, policy, technology, and determinants of micromobility usage. It highlights micromobility's potential to be a sustainable and effective low-carbon solution [26]. Oeschger et al. [2] conducted a systematic literature review focusing on the integration of micromobility with public transport. They provided a comprehensive collection and critical analysis to highlight the characteristics of related research. It identifies research gaps and suggestions for further bracing such successful mixing. However, none of the three $([2,25,26])$ address the integration of multiple topics into the framework of a life cycle perspective. Assessing emerging research areas and aggregating them into a life cycle thinking (LCT) approach is critical for clarifying whether micromobility is a trend or a hype in sustainability [27].

This paper's aim is to present a critical literature review on recent papers to highlight the current state of knowledge on micromobility-related modes while also evaluating the relationship between its application and other research topics. The goal is to focus on recent trends, so the work focuses on scientific materials recently published [28]. Hence, it provides an overview of multiple research areas to provide appropriate policy recommendations and propose an LCT approach to micromobility. The significant contributions are, first and foremost, the identification of existing gaps and emerging opportunities in R\&D. Second, to provide a critical overview that will allow researchers and policymakers to define strategies based on the current state of the art, trends in the micromobility sector, and the need for actions to ensure the sustainability of emerging micromobility solutions and products.

The structure of the paper is the following: Section 2 describes the materials and methods used, followed by the literature review results. Section 3 is divided into two subsections: Section 3.1, Environmental Appraisals, and Section 3.2, Parallel Research Areas of Micromobility Sustainability-Socio-Economic Appraisals. In Section 3.1, we review the LCA studies related to micromobility vehicles, focusing on indicators such as energy consumption and GHG emissions, not before highlighting the users' perspectives on noise and pollution exposure. The second sub-section reveals the reviewed work in inherent areas related to the micromobility transport system and its socioeconomic sustainable integration. As the initial figure of Section 3 shows, it leads to the identification of emerging research areas, which are included in the proposal of an LCT framework. Both are presented in the discussion (Section 4), before concluding in Section 5.

\section{Materials and Methods}

The major source of materials for this literature review is a collection of scientific papers, books, journals, and technical reports. The first stage of the adopted methodology consisted of performing initial research, deliberately broad. As a search engine and database, this work relies on ScienceDirect, Scopus, and other available online tools-such as Mendeley Desktop [29] and Web of Science [30] — to acquire and select the resources for research while collecting them in a reference manager [31,32]. The software application VOS Viewer [33] was then used to obtain an overall visualization of addressed topics, which configured a first bibliometric analysis of the collected materials. Other tools such as websites were occasionally used to collect, choose, and treat the resources, for instance, to check for co-citation or cross-referencing.

At this initial stage of text material acquisition, we mostly restricted the selection according to their publication date-from January 2014 to October 2021—and at least one of the listed keywords had to be included in any field of each record's text. Likewise, we only considered English language texts.

List of keywords:

- Micromobility;

- Transport(ation);

- Active modes;

- Bicycle;

- Pedestrians; 
- E-scooters;

- Life cycle thinking (LCT);

- $\quad$ Life cycle assessment (LCA);

- $\quad$ Life cycle cost (analysis) (LCC);

- (GHG) Emissions;

- Sustainability;

- Security;

- Safety;

- Energy;

- (Big) data;

- Crashes;

- Injuries.

As a result, the initial research yielded 360 records based on the criteria that were initially established. According to Figure 1, these have a distribution of publication dates that demonstrate the growing interest in micromobility. The drop in the number of publications for 2021 is due to the fact that those published in the last third of 2021 were not considered at the time we conducted the research. Therefore, this does not indicate that the scientific community's interest in the topic will decline in the following years.

\section{Publications per year}

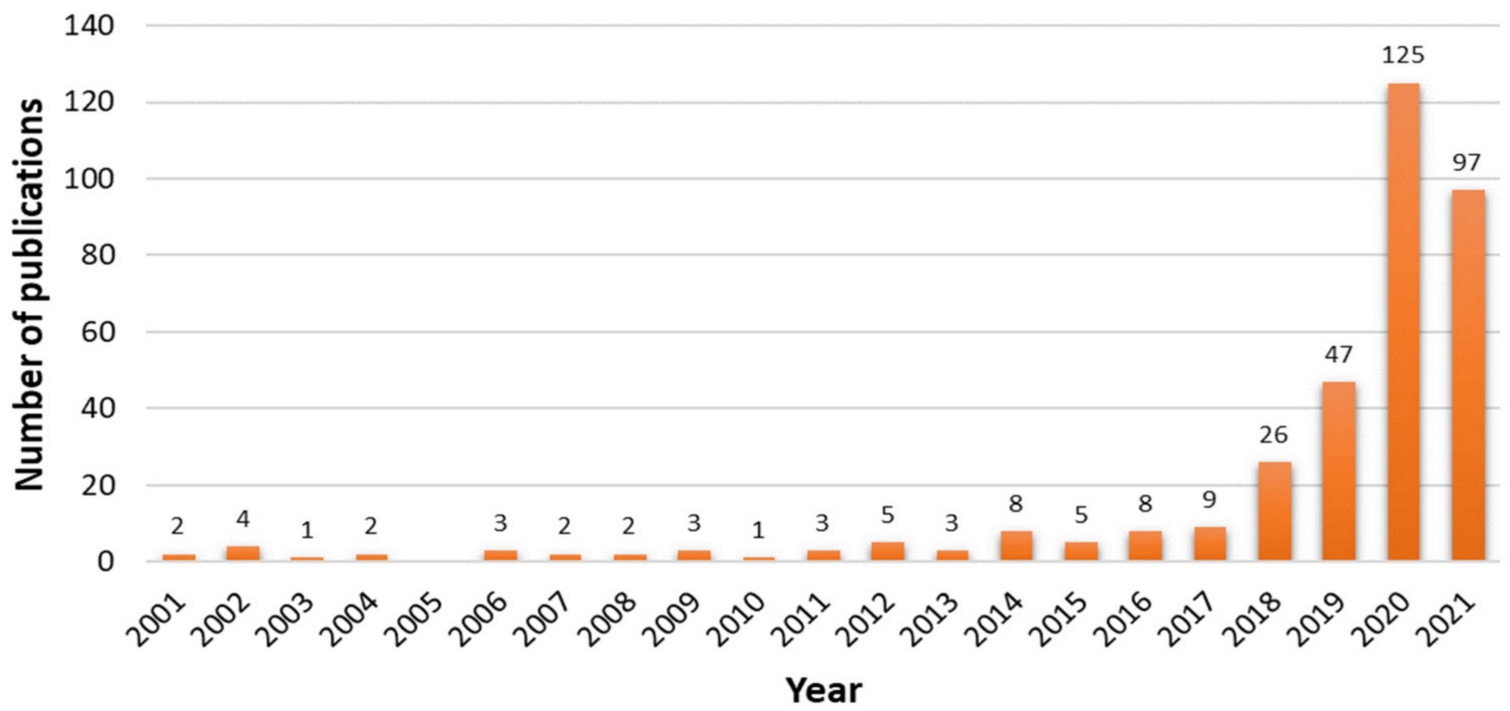

Figure 1. Micromobility-related publications per year.

The second and third stages of the methodology take care of research refinement. At the second stage, to select a shorter list from the initial research, we used the Mendeley Desktop tool to evaluate which records combined two or more of the above-listed keywords. Additionally, we resorted to the number of citations, the impact factor of the journals, and the authors' h-index. Then, the work relies on our critical element to analyze the content of each record, verify which research questions are addressed by the authors, identify the relevance of their results or the presence of hints regarding emerging research needs or LCT. Each of the cited records had to include at least an indicator of future work on micromobility, thus contributing to the identification of R\&D needs or regarding the application of life cycle methodologies.

Finally, at the fourth stage, we resort to VOS Viewer to perform the final bibliometric analysis and confirm that after restricting the initial 360 resources to the final number of cited ones, we were still covering the whole scope and purpose of this aggregating literature review. Through using that tool, we are able to check the co-citation and co-occurrence 
of topics between cited references, visualize their distribution across the timeframe, and detect gaps in our research work.

The summary of tasks of the methodology and used materials is seen in Figure 2.

\begin{tabular}{|c|c|}
\hline Stage1 - Initial research & \\
\hline \multicolumn{2}{|c|}{$\begin{array}{l}\text { - Search in Scientific Databases - Scopus, ScienceDirect } \\
\text { - Collection of References - Mendeley } \\
\text { - Overall visualization analysis of topics addressed per year on title and abstract - VOSviewer }\end{array}$} \\
\hline Stage2 - Data selection & \\
\hline \multicolumn{2}{|l|}{$\begin{array}{l}\text { - Different combinations between keywords } \\
\text { - Identification of most cited works and documentation of main authors } \\
\text { - Iterations in numerous stages based on inclusion/exclusion criteria }\end{array}$} \\
\hline Stage3 - Content analysis & \\
\hline \multicolumn{2}{|l|}{$\begin{array}{l}\text { - Documentation of addressed research questions } \\
\text { - Evaluate the value of results and perform critical analysis } \\
\text { - Scrutinize conclusions and judge emerging research needs }\end{array}$} \\
\hline Stage4 - Bibliometric Analysis & \\
\hline \multicolumn{2}{|c|}{$\begin{array}{l}\text { - Analysis on co-authorship and co-citation } \\
\text { - Visualization on the preponderance of each keyword based on occurrences per year - VOSviewer } \\
\text { - Detection of gaps and integration into life cycle thinking framework }\end{array}$} \\
\hline
\end{tabular}

Figure 2. Schematic of methodology and materials.

Both at the first and fourth stages of the methodology, the software application VOS Viewer was used to ensure a broad review of related themes, mainly including the sustainability pillars, i.e., social, environmental, and economic sustainability. It investigates the degree of interconnectivity between the whole group of 360 records or the final group of 138 adopted references, mainly to understand the networking effects between topics, keywords, and the co-citation of authors. So, this enables the building of correlation maps, as later seen in the results and discussion sections, making use of the main topics or main keywords chosen by the cited authors. There, one and only one link exists between any two keywords. Such links, which appear as lines in the figures, can reflect the number of publications in which two terms occur together. The numerical value is not shown in the figures. However, it is reflected in the spatial distribution of the terms and helps the reader to understand the connections between topics throughout the network [33].

For the whole research performed, it was not an exclusion criterion if the paper addressed issues related to goods and not passengers' mobility, or vice-versa. In any case, most of the presented literature review results focus on PMDs for an individual's mobility. The only exception is referring to operational services when mentioning shared mobility and Mobility as a Service (MaaS) concepts, such as mentioning vans dwelling in cities to pick up dumped e-scooters.

\section{Results-Literature Review}

In this section, the results of the literature review are presented. The section is divided according to the abovementioned division to enhance the splitting between environmental and socio-economic dimensions of the sustainable integration of a micromobility transport system. It presents the results from the bibliometric analysis performed at stage one, before explaining the results from the detailed literature review. Figure 3 is a schematic representation of how the results are presented to support the discussion chapter. 


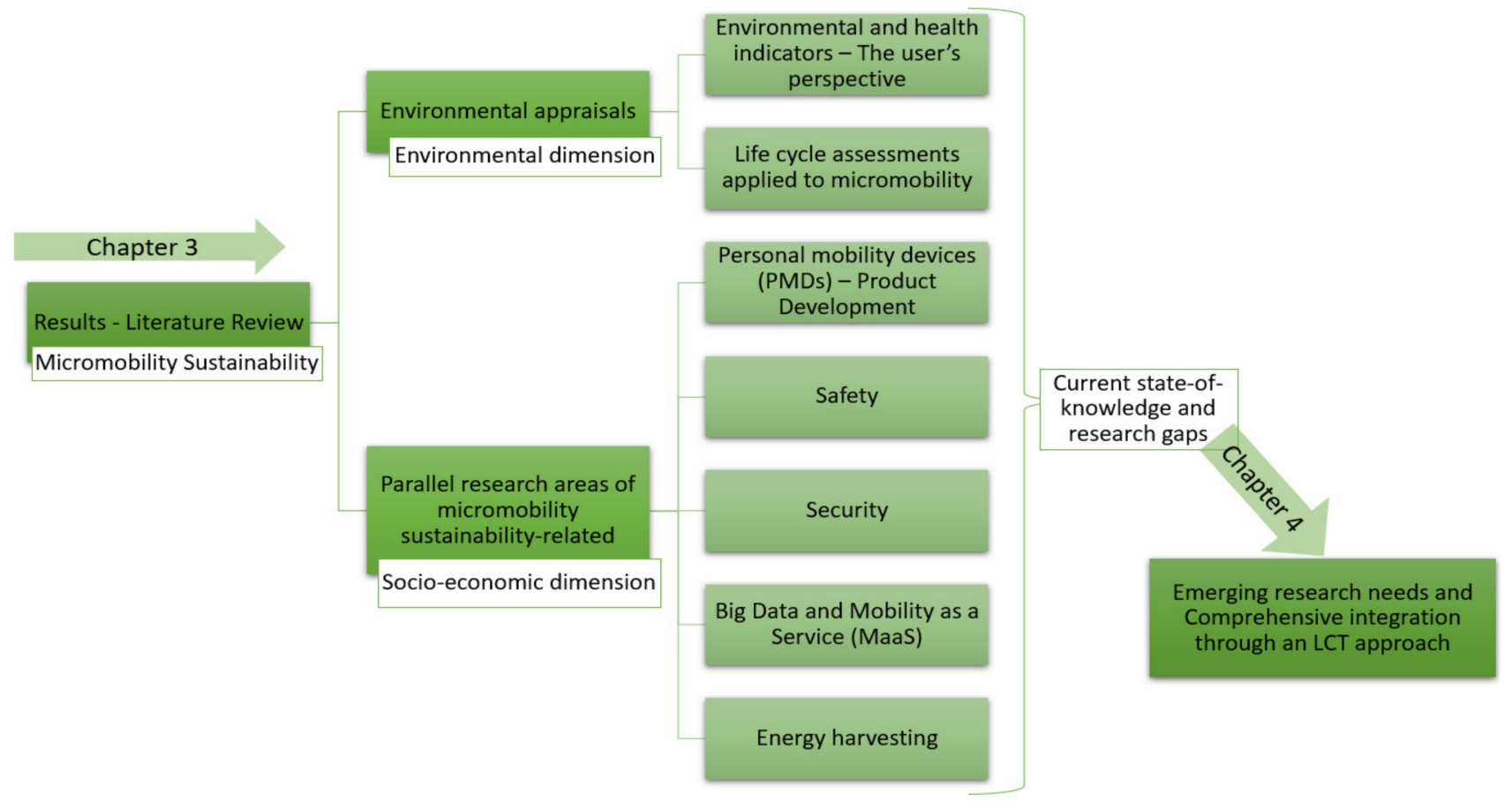

Figure 3. Structural organization of results.

The initial group of records was scrutinized to obtain the general visualization of researched items with a chronological distribution, which guaranteed the desired broadness of the research to integrate all the recent developments and identified research gaps into a life cycle thinking approach. Figure 4 is the result of an analysis of the titles and abstracts of the documents. There were 192 terms used by the peers that appeared in at least 10 different records from the initial group of 360 materials. The figure shows the 115 more relevant ones based on the calculation performed by VOSviewer.

\subsection{Environmental Appraisals}

\subsubsection{Environmental and Health Indicators-The Users' Perspective}

Micromobility modes such as bicycles, e-scooters, lightweight PMDs, and walking can help to minimize pollution and noise in cities. However, these modes operate in crowded traffic areas, so the users are still exposed to particles and multiple sounds [13]. The health organizations even suggest that people with respiratory and cardiovascular problems should avoid outdoor activity if the concentration of specific pollutants is high [34]. Furthermore, a recent data analysis following a mixed-method campaign has revealed an ambiguous trend in how society assesses the themes of noise and environmental pollution. Most cyclists underestimate their exposure. Nevertheless, users' answers revealed that if any technological tool advised it, the majority of them would consider adopting alternative paths for reduced exposure [35]. The users' perspective is, therefore, crucial to the successful and sustainable implementation of micromobility.

As a result, several authors have dedicated their research to evaluating the impact of air pollution and noise on pedestrians and cyclists [36-38]. A study focusing on short-term noise and air pollution exposure in Montreal demonstrates that cyclists are currently far more exposed to noise and $\mathrm{NO}_{2}$ inhalation than motorists in vehicles or people combining different mobility modes. The study also confirms that the health benefits of cycling - which involves significantly more physical effort-are far greater than those of other mobility solutions [37]. Similarly, a study found that bikers are considerably more exposed to particles from vehicle exhaust systems than any car driver in three European cities [38]. Hence, the authors suggest that cities should plan infrastructures to promote active modes because the benefits of physical activity outweigh the risks. Such suggestion is consistent 
with three suggested actions for the city of Curitiba, Brazil: installing cycleways in streets with fewer vehicles, employing ventilation to disperse pollutants, and reducing obstacles such as bus stops and intersections. In addition, traffic light synchronization and vehicle conversion to hybrid or fully electric could help decrease the risks, particularly those related to pollutant inhalation. Regarding traffic speed control, it is unclear whether the creation of wide traffic calming areas will increase or decrease the exposure [39].

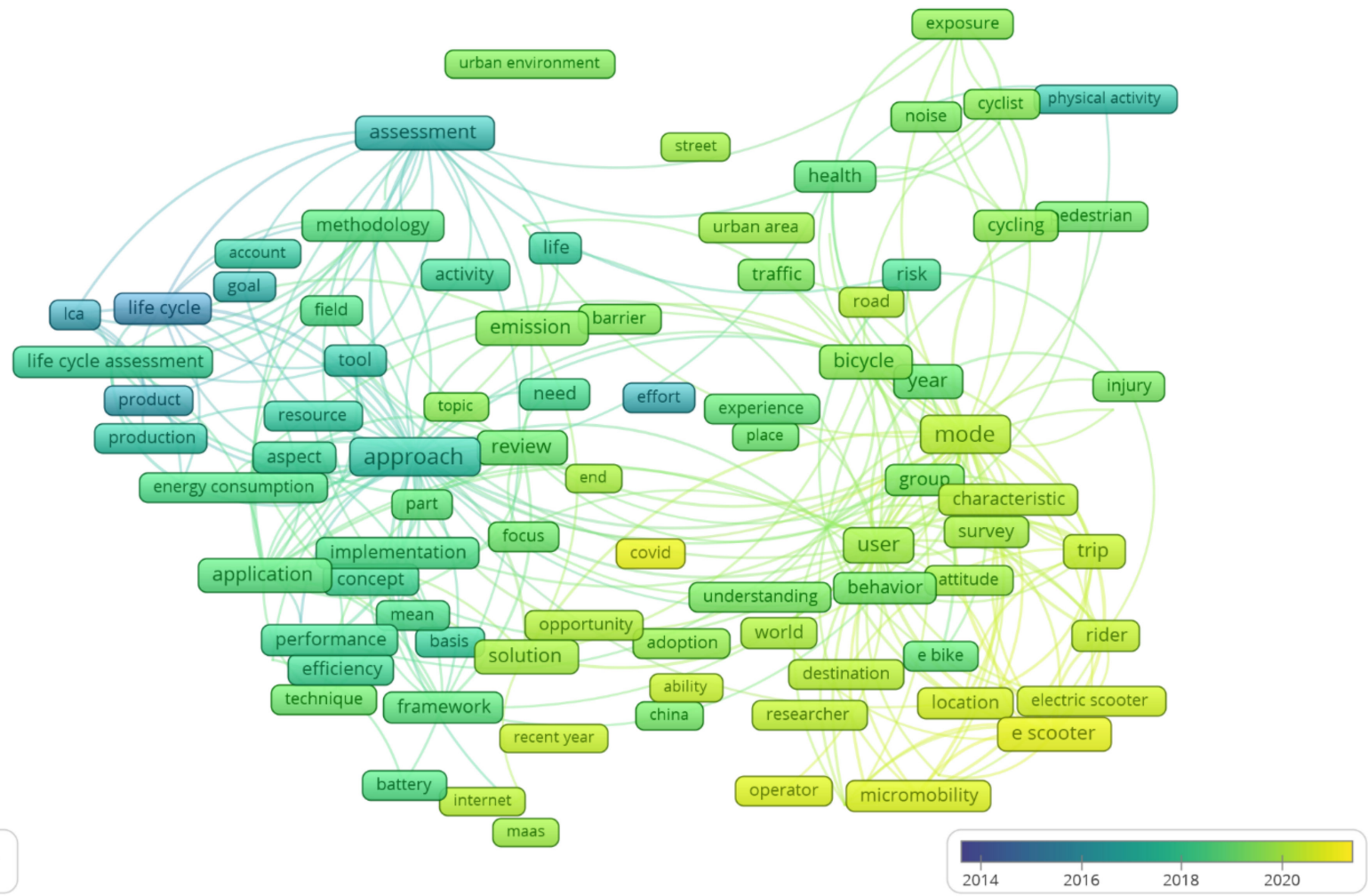

Figure 4. Overall visualization analysis of topics addressed in the titles and abstracts of all 360 records.

However, when establishing integrated indicators of exposure-such as the sustainability indicator developed by Fernandes et al. [40], which incorporates traffic-related externalities while considering the different local contexts-those four studies ([36-39]) overlook the inclusion of new PMDs. Likewise, researchers often recognize the need for more studies evaluating the levels of noise exposure (also considering the predicted contribution of automated electric vehicles to traffic noise reduction). At once, new research should reflect the fact that when multiple commuting modes are used, the exposure may be greater than if exclusively cycling because of the surrounding high noise levels from subways, trains, buses, and other vehicles [36,41].

Therefore, the emerging research needs can rely on experimental research and physical investment in infrastructures to promote environmental and health sustainability from the users' point of view. Such investments can be guided by numerical and modeling studies such as the one performed by Santiago et al. [42]. Their estimation of pedestrians' $\mathrm{NO}_{\mathrm{x}}$ exposure integrated CFD models with microscale pedestrian mobility models, which can enable the transition from collective to individualized exposure assessment, allowing for a more accurate estimation of total daily exposure. Despite the fact that the study does not provide clear conclusions on collective public health, its key innovation is that it provides valuable information for air quality management [42]. This highlights the possibility of supporting initiatives related to management strategies and urban design. Specifically, where to monitor air quality and where to implement steps, such as those for Curitiba.

Additionally, long-term all-cause mortality, which is strongly related to physical effort and pollution exposure, is a relevant health indicator $[43,44]$. Through the development 
of a health effect assessment model, researchers were able to conclude that walking and cycling lower all-cause mortality even when air pollution is high [45]. However, short-term fluctuations in pollutant concentration have an impact on daily mortality and morbidity. As a result, these are predicted to have some impacts on estimates of long-term all-cause mortality risks from active commuting [45]. Despite that, the impacts of wearing protective face masks while moving through active modes have yet to be studied, primarily because their use is usually disregarded and lately because their efficiency depends on personal characteristics as well as the sort of protection chosen [46]. Moreover, acquiring experimental data from users who utilize face masks during physical effort in the current COVID-19 pandemic context is an emerging research opportunity to pursue. So, to clarify how much short-term variations in pollutant concentration impact long-term mortality simulations remains a research need that could benefit from experimental data on how the users protect themselves from pollution by wearing masks.

\subsubsection{Life Cycle Assessment Applied to Micromobility}

Another viewpoint on the sustainability of micromobility solutions is the one that quantifies their impacts using LCA. This approach is frequently required to demonstrate a balance between the environmental, economic, and social sectors [47]. An LCA typically consists of four stages: defining objectives and scope, the inventory, impact assessment, and interpretation. The studies adopt a functional unit for evaluating impacts regarding energy consumption and greenhouse gas emissions (GHG) [48]. The systems' boundaries often identify the stages of indicators' examination from primary production to the end-of-life or recycling stage. According to Hollingsworth et al. [49], these include pillars such as manufacturing, transport, infrastructure, energy, and operational services.

However, LCA is a technique seen as a limited and isolated method of assessing sustainability across all three pillars. As a result, the literature suggests three potential solutions. Firstly, the indicators should be broadened to incorporate social and economic impacts together with environmental ones. Secondly, by expanding the analysis' scope from the product level to the national and global levels. Thirdly, with the addition of new mechanisms to care for systems' interoperability, including uncertainty analysis or stakeholders' involvement [50,51]. Additionally, Petit-Boik et al. [52] conducted a review that presented many life cycle perspective strategies, research gaps, and methodological flaws in multiple sectors. It exposed the need for better assessments, specifically from the standpoint of sustainable urban cities, noting that integrated schemes combining life cycle tools and methodologies can help with urban complexity, particularly for largescale systems [52]. This proves that a deeper and broader LCT approach is applicable to a range from single products to more complex systems such as cities or to the concept of micromobility.

Nevertheless, LCA studies on micromobility vehicles have produced results that spark debate and highlight the need to seek out the three pillars of sustainability since they mainly focus on environmental appraisals. In the specific case of Hollingsworth et al. [49], they estimate a GHG emissions value of $202 \mathrm{gCO}_{2 \mathrm{eq}}$ / passenger-mile for e-scooters, owing primarily to materials selection, manufacturing processes, and operational services. Likewise, in Germany, e-scooters have a global warming potential estimated at $165 \mathrm{gCO}_{2 \mathrm{eq}} / \mathrm{km}$ [53]. Furthermore, the Ghisallo tricycle, a novel micromobility vehicle, was estimated to have lifetime indicators of $0.36 \mathrm{MJ} / \mathrm{v}-\mathrm{km}$ and $15.29 \mathrm{gCO}_{2 \mathrm{eq}} / \mathrm{v}-\mathrm{km}$. For the latter, the production stage is responsible for $42 \%$ of GHG emissions and overall, energy consumption and GHG emissions can reduce by $25 \%$ and $45 \%$, respectively [54]. Moreover, an LCA conducted by Coelho and Almeida revealed that the production stage of a mountain bike is the most damaging to the environment. Steel and aluminum are extensively used in the wheels, fork, and frames [55]. These could be replaced with bamboo, which has been discovered to be around 50\% less toxic and 30\% less harmful than aluminum and steel, respectively [56].

Even if the three abovementioned suggestions have yet to be considered for achieving the full potential of LCT approaches, all the authors from the latest five cited works 
([49,53-56]) advise strategies to reduce environmental impacts. That type of sensitivity analysis looks into the effects of changing the input assumptions for the life cycle pillars. Changes in battery production and recycling, the charging of batteries with a greener energy mix, lifespan changes based on mileage, and shorter collecting distances of operational services are just a few cases. Thus, like Hollingsworth et al. [49] found, environmental indicators analysis must include skepticism.

For example, in Paris, free-floating e-scooters might generate an additional 13,000 emitted $\mathrm{CO}_{2 \text { eq }}$. Therefore, GHG emissions and energy consumption resulting from the micromobility sector must be carefully examined based on the requirements of each city and the type of micromobility mode [12]. Similarly, the rise of e-moped shared scooters has generated concerns about the business model's long-term sustainability since the worst-case scenario can be $40 \%$ more hurtful than the original one. Promisingly, the best-case scenario includes solar-powered e-mopeds and batteries swapped with the assistance of an electric van to achieve $20 \mathrm{gCO}_{2 \mathrm{eq}} / \mathrm{p}-\mathrm{km}$ [57]. So, the study by Schelte et al. [57] suggests reducing the impacts of aluminum through recycling processes or using renewable energy sources in the manufacturing stage of micromobility vehicles. Moreover, the typical operational services performed by vans might start to be replaced by electrical cargo bikes. These have the potential to cover up to $10 \%$ of the two-kilometers-long trips. It is estimated that a life cycle impact from well-to-wheel can reduce $\mathrm{CO}_{2}$ emissions by $73 \%$ [58]. The penetration of renewable sources might also contribute to reducing the impact of powered cargo bikes. For those, more than $20 \%$ of the life cycle $\mathrm{CO}_{2 \mathrm{eq}}$ emissions are due to electricity production, based on the European mix of 2021, which may be mitigated if renewables replace fossil fuels [59]. Finally, Schelte et al. [57] advise on the importance of considering other socio-economic sustainability factors such as road safety in further research.

\subsection{Parallel Research Areas of Micromobility Sustainability—Socio-Economic Appraisals}

The environmental appraisals section of the literature review suggests that the LCT of micromobility includes R\&D needs in many areas, from the standpoint of users' health improvements or from the standpoint of environmental sustainability. From the perspective of the socioeconomic dimension of sustainable integration, micromobility inevitably relates to research on how society engages in new business models, how infrastructures give a sense of safety to the vulnerable road users, how digitalization confers a sense of security to the system, or how renewable energy sources penetrate the system. Hence, in Sections 3.2.1-3.2.5 we reveal studies and identify research gaps related to PMD manufacturing or product development, security, safety, the inclusion of micromobility under the MaaS concept, big data treatment, and energy harvesting.

Regarding life-cycle cost evaluation, there are some papers that apply it to micromobility. A new methodology for a highway project-level life-cycle benefit/cost analysis that addresses certainty, risk, and uncertainty could provide a way for transport agencies to explicitly address uncertainty issues, thereby improving on the currently existing risk-based life-cycle cost analysis approach [60]. Perhaps the crucial concept of risk management in transport could aid in addressing the issue of life-cycle cost evaluations in the road planning and design process, which is particularly challenging owing to a lack of relevant data [61,62]. Moreover, life-cycle cost analysis, including pavement selection, could help to address the previously mentioned gap in the LCT approach to micromobility systems, which does not account for the impacts related to infrastructure and pavements $[17,63]$. The literature review even shows that, usually, investing more money "up front" reduces the global warming impact and life-cycle cost of pavements, in particular for bridges. It suggests that low traffic-volume pavements can get more expensive in lifespan if frequent maintenance is required [64]. Additionally, an LCC analysis of railway tunnels shows that more cost-effective construction measures and more environmentally friendly materials are required since the building stage contributes to most of the life-cycle costs and $\mathrm{CO}_{2}$ emissions [65]. To estimate costs of micromobility-related infrastructure, it is an emerging 
research opportunity to use either the LCC approach or the RAMS (reliability, availability, maintainability, and safety) analysis, a method also mentioned by Kaewunruen et al.

Moreover, our literature review revealed that the inclusion of a social perspective when calculating the cost of an electric bicycle is crucial. Most of the studies consider the acquisition costs, battery replacement, charging, and repair and maintenance costs from the perspective of the economic side of the buyer's point of view. However, the consideration of social and environmental impacts, including traffic-related costs, the processing costs of battery scrap, and pollution costs in the life cycle of an electric bicycle led to the conclusion that motor vehicles still have a better ratio between consumer costs and social costs. As a result, emerging research needs are identified, and they include more effective recycling networks for the batteries, as well as the establishment of a deposit refund system to reduce the costs of waste managing through an increase in the recycling rate, together with strong legislation to prevent pollution at the source, which is cheaper than eliminating pollution [66]. As for the side of the public investment of funds in infrastructure, the life cycle cost-effectiveness is also evaluated. For instance, to the city of Stockholm, investment costs over a 50-year life cycle are offset by healthcare costs and compared with estimated long-term impacts on morbidity, quantified in disability-adjusted life years (DALYs). Investing in urban infrastructure to increase bicycling is cost-effective from a healthcare perspective. Yet, these studies should, in future, account for societal benefits such as obesity reduction and environmental effects such as air pollution concentration decreases due to multiple factors, since the authors believe the cost savings and health benefits are underestimated [67]. Alternatively, a life cycle cost analysis could consider the recent disruptive innovations and research needs in each of the following five themes, with impact on economic sustainability or with social impacts, such as in the form of safety costs.

\subsubsection{Personal Mobility Devices (PMDs)—Product Development}

Personal mobility devices (PMDs) include, but are not limited to, wheelchairs, scooters, bicycles, and skateboards. The potential of PMDs to explore first/last/only mile options increases their attractiveness [68]. As a result, innovation on products to support walking, cycling, and other micromobility activities raises challenges about the engineering context at the manufacturing stage.

The recent popularity growth of PMDs in cities has placed the focus on their portability. Portable and inflatable mobility devices, which have lately been proposed, address both portability and injury prevention challenges. These use newly discovered materials that enable reversibility via inflation and deflation. Moreover, a scan-based design system allows an interactive and iterative design approach for more efficient and injury-free product development. So, their ability to be customizable and the concept of inflatable frames, wheels, and steering mechanisms anticipate the R\&D-related need to carefully select eco-friendly materials based on the properties and mechanisms for developing inflatable products [69]. Such research on manufacturing portable, inflatable PMDs may have an impact on social sustainability indicators such as comfort, safety, and ergonomics.

Any innovative product development might follow general specifications such as those proposed for heavy-duty cargo bikes by Bogdanski et al. [70]. Cargo bikes are identified as useful for urban logistics. However, little research is available yet and due to operational issues, their implementation is not so fast. Currently, these can only transport parcels and not pallets. Moreover, the size and weight of the parcels limit the distance covered. Hence, future studies should address new light and sustainable materials to expand the number of businesses using this logistical tool [58]. In any case, Bogdanski et al. [70] proposed specifications for a registration-free cargo bike that should be safe, easy to ride, and has an easily accessed chassis to repair parts. Similarly, their findings highlight the need for designing standardized and non-proprietary bodies to guarantee a smooth logistic process if the cargo bikes operate like the heavy trucks and their coupled bodies. Moreover, they advise that an emerging change has to be performed since, currently, the street planning of most countries does not consider these eco-friendly vehicles [70]. 
Aside from outdoor personal mobility vehicles, another field of research is developing new PMDs for indoor use. A suggestion is to employ the AngGo platform, a shared indoor smart mobility device, in situations where walking long distances may be difficult for a portion of the demanding population. The development of this device still lacks the operationalization of autonomous or manual drivability systems [71]. Likewise, an Elderly Personal Mobility Device (EPMD) equipped with sensors and Internet of Things (IoT) technology detects air quality and other critical environmental, health, and social parameters. The EPMD design involves multiple stages of product development, including chassis material selection, electric equipment, and sensors selection. To achieve social sustainability improvements, future research on autonomous driving will rely on ML algorithms to further improve this new PMD [72].

Even though Section 3.2.2 addresses safety-related studies, product development might bring social impacts as it serves the purpose of injury prevention. From the findings of Fernandes and Sousa's [73] literature review on motorcycle helmets, which focused on the causes of head injuries, head impact protection, and energy absorption, it was stated that rotational acceleration was generally accepted among researchers as the primary mechanism of brain injury. Nonetheless, helmet impact testing was not completely solving the problem [73]. As a result, R\&D efforts must study the protection enhancement on other realistic impact parameters, which will lead to new product development. Such could build from the promising results regarding oblique impacts that were obtained by using a WAVECEL cellular structure. It seeks to reduce the shear stiffness of the helmet by introducing a collapsible structure, and the tests aim to mitigate rotational head acceleration in the case of impact [74].

Additionally, from a lifetime cost-effectiveness perspective, little is known when addressing the use of helmets on a mandatory basis. For the Dutch context, through decision tree modeling it was concluded that the inclusion of legal enforcement to increase the use of helmets could be cost-effective, especially for people over 65 years of age, who are more exposed to the risk of a traumatic brain injury. However, to make it cost-effective in all age groups it is suggested that the prices of helmets should decrease by $20 \%$. Such a decrease is mentioned as non-hypothetical due to large-scale production and sales while opening the door for an emerging research need for safer helmets with lower costs and ecofriendly materials. The authors also recommend future research to address the mechanisms behind the cycling risks and the acceptability of the mandatory use of helmets considering that injury risks differ substantially according to the location in the world [75].

\subsubsection{Safety}

Meanwhile, the number of crashes involving PMDs and motorized vehicles has been quickly and alarmingly growing [76,77], as well as reported injuries [78,79]. Over 61 days of analysis in 2018 only in Indianapolis, there were 92 injuries from electric scooter users [80]. At once, users still perceive safety concerns as barriers to using micromobility modes. From 1256 people enquired, 30-60\% were concerned about striking or being hit by someone. Fewer than $10 \%$ cited increased safety as a benefit of riding an e-scooter [81]. Perhaps because, as the study of Hashimoto et al. [82] reveals, more data is required to fully evaluate the safety of PMDs' co-existence with other vehicles.

Unfortunately, unlike motorized vehicles, there is a scarcity of crash-related data regarding e-scooters in the US, making extensive crash characterization difficult. Yang et al. [83] studied the safety of a PMD by compiling media reports from search engines such as Google News. This was due to a lack of open data platforms with more realistic accident data reports. As a result, it underlined the need for a comprehensive and automatic way of reporting crashes for further safety analysis. Zagorskas et al. [84] also identify a research gap linked to the categorization of data from crashes with e-PMDs.

There have also been concerns regarding the safety of e-scooter riders and of those sharing roads and sidewalks with them. A pedestrian injured by an electric scooter may face financial burdens due to time off from work and medical costs, and the differences in 
local rules make it difficult to normalize policies. So, future studies should characterize the type of pedestrian injuries in multiple places and verify which local laws would work better to finally inform policymakers in regulating micromobility modes [85].

Albeit some scarcity, existing data from surveys helps to evaluate how pedestrians feel about risk variables such as improperly parked dockless e-scooters. From 181 e-scooter riders and non-riders asked about how often they are blocked by e-scooters on sidewalks and how they feel, $38 \%$ of non-users feel unsafe and $45 \%$ of users and non-users often see blocked sidewalks. Therefore, a more comprehensive look at sidewalk barriers is suggested to assess if micromobility vehicles are really impeding people's mobility or threatening their safety [86].

Equally, data shows that from 2015 to 2019, the process of battery charging caused 330 fires associated with charging and riding self-balancing scooters [87]. So, as a result of the failure of high-density lithium-ion (Li-ion) battery packs powering the PMDs, there has been a rise in burn injuries from PMD-related fires [88]. Separator shutdown, flame retardants, and cell venting are three viable solutions when considering measures for lowering that number. However, there is still a research vacuum that must be filled so that fire situations can be treated, ensuring quick fire extinguishment without sacrificing battery performance [89].

Therefore, if the datasets grow, finding risk variables will become more important for decision-makers who develop road safety measures, regulations, and plans. Particularly if considering another challenge, which is the rise in the average speed of the vehicles present on the streets. As the number of e-scooters on European streets has surpassed that of traditional bicycles, this has social and planning consequences such as street space management and crash prevention.

Fortunately, risk factors that determine the severity of vulnerable road users can be accurately predicted using a decision tree and logistic regression, two supervised ML classifiers [90]. Additionally, changes in data collection that allow for the grouping of pedestrians' and cyclists' exposure by age and gender or with vehicle, road, or driver details should assist in improving the research outcomes. A good example is the multinomial logistic regression for predicting vulnerable road users' injury risk [91]. Besides, acquiring data regarding the detection, characterization, and prevention of crashes with PMDs is an emerging research area, mostly through ML algorithms that promote road safety modeling since the potential of crash modeling techniques is above that of traditional statistical models [92]. As a result, big-data treatment, analyzed in Section 3.2.4, is a valuable instrument for the future assessment of individual and collective safety issues related to PMDs.

\subsubsection{Security}

Concerning security issues, all the involved parts of intelligent mobility systems are vulnerable to any breach of security, and a thread of security issues arises. These issues are primarily caused by communication channels between service providers and PMD users' smartphones. According to a qualitative study, elderly users lack confidence in adopting information and communication technologies applied to mobility networks owing to financial and security issues regarding smartphones and internet usage [93]. Furthermore, several survey respondents in Portland expressed concerns about the data's potential use, especially, with the misuse of GPS data to track their travels when using smart mobility apps or the misuse of financial information due to cellphone loss or theft [94].

This process typically includes the users or riders, their smartphones, and internet systems through the cloud. The attackers can be the rider/user, any outsider, or the service provider [19]. Nonetheless, research on the security of micromobility modes equally includes the vehicle's security to cover all bases. Vinayaga-Sureshkanth et al. [19], for example, propose defenses for potential attacks, as well as guidelines for future studies on new technologies. It advises that service providers assign e-scooter chargers with the ability to verify the device's vitality to avoid physical harm. 
Similarly, implementing cryptographic solutions as a countermeasure to eavesdropping is proposed to avoid sensitive information leakages. Countermeasures such as new anti-spoofing and anti-jamming solutions that rely on additional sources and sensors are also offered, obviating the need to evaluate the capabilities of various sensors in smartphones. These are primarily concerned with the tracking of e-scooters via the Global Navigation Satellite System (GNSS) module through GPS [95].

Finally, potential attacks compromising the privacy of users' data relate to the treatment of such data, which is typically provided by the users to the service providers and is shared with third-party partners such as local governments. Recently, it has been demonstrated that new vulnerabilities severely impair ride-hailing systems and that present solutions are not yet abundant, while data-collecting attacks are clearly feasible [96]. Thus, the findings from the literature review point to emerging research gaps, including the interconnectivity between security issues, mobility service providers, big data, and regulation, policy, and administration sectors.

\subsubsection{Big Data and Mobility as a Service (MaaS)}

As previously stated, the increasing collection of micromobility-related data may have impacts on the safety and security sectors. Meanwhile, governments and researchers are stepping up to make use of big data tools' potential to enhance the performance, accuracy, granularity, and quality of smartphone-based mobility data [97-99]. Data acquisition for e-scooter use is a good example. Specifically for the topic of spatiotemporal usage patterns, which supports the opinions of users, transport planners, and policy stakeholders, data collection and analysis methods are still based on surveys rather than the suggested method of leveraging real-time vehicle big data. This type of R\&D improvement will provide a plethora of data that will aid in understanding how people travel in cities [100].

More in-depth scientific knowledge on e-scooters and other PMDs users' choices and patterns (spatiotemporal), in particular, is still required [101]. According to the results of a survey with 459 answers, people using e-scooters in Paris rarely own their PMDs. They are mostly replacing trips that were previously made by walking or taking public transport. As a result, the authors advocate for the use of bigger data sets, including behavior observations and users' attitudes, safety issues, maintenance, and charging habits [102].

However, using big data to infer travel demands has its downsides. It is difficult to assess the human activities that occur during a journey. For instance, it is vital to understand what happens if a PMD is dropped and what activities the user will engage in [103]. A quantitatively obtained estimation of the spatiotemporal bike-sharing impact using a big data technique demonstrates this. Such a study faced issues with big data analysis, which impacted the results of the bike's environmental benefits. Similarly, privacy concerns led to a database in which trips are chronologically unordered and only provide information related to starting and ending points, hiding the distance and path taken by the users [104].

The use of big data is also related to the concept of MaaS to support the development of micromobility, which emphasizes the socioeconomic sustainability potential. MaaS has been identified as one of the potential solutions to mobility issues, despite the fact that its progress from pilot to large-scale systems and the specification of which mobility modes has been progressing slowly [101]. In any case, several authors found that early adopters of the MaaS concept for micromobility are primarily people under the age of 55, with good socio-economic conditions, who frequently travel on vacation and use planes and trains [105]. Moreover, according to a recent study from Zagorskas et al. [84], the MaaS concept has benefited from the existing network of carsharing services that have offered e-scooters in Europe. Therefore, it appears that understanding and clarifying the potential of MaaS for micromobility and other trip types is an emerging research need.

In addition, shared micromobility services can generate real-time data such as spatiotemporal travel patterns and behaviors [106]. For instance, future work using more refined spatiotemporal data on micromobility trips could help to confirm that these are significantly faster than other vehicles, including the relationship between metro stations 
and micromobility trip origins and destinations [107]. Moreover, if privacy concerns fade and data sharing becomes open on a secure network, demand models that generalize how people use e-scooters under the shift towards the MaaS paradigm will be better supported [108]. Using this approach, different configurations of e-scooter sharing systems using PMDs under the MaaS concept have revealed that fleet management, energy storage, battery management, and other factors all have different impacts on the trade-offs between users' satisfaction and the associated costs to the service providers [108]. Even more, a real-time monitoring algorithm deals with big data to understand the spatial and temporal requirements of managing a micromobility fleet. It is suggested that the technology be applied to other modes of transport and that the methodology be improved to promote lower computational costs associated with big-data treatment for MaaS support [109].

The integration of different micromobility vehicles into vehicle fleets to actively promote MaaS also depends on further studies on all sustainability dimensions. An economic study has shown that mobility costs can be significantly reduced when smart multimodal mobility systems integrate different means of transport. Further research should be performed regarding which modal split is desirable for (corporate) MaaS systems and to recommend which means of transport could be used. For this, social life cycle assessment methods and integrated approaches to life cycle sustainability assessments are suggested [110]. Likewise, it is suggested to understand the size of the fleets under different scenarios. For instance, a simulation based on MATSim to assess the economic impacts of shared e-moped scooters showed that the larger the fleet, the more and longer trips that are taken by car in Berlin can be replaced [111]. Likewise, vehicle allocation management can be modeled to identify the best and worst vehicles of a fleet based on their mission, age, fuel type, miles per gallon, and cumulative mileage together with a life-cycle cost analysis for each vehicle. This might finally allow the application of the Logic Scoring of Preference methodology to the asset management of a vehicle fleet, comparing all the vehicles before making decisions [112].

Finally, the context of big data availability relates to transportation asset management (TAM) which fits well in the context of smart cities. Big data and advances in techniques are expected to provide the world with extra capability for optimal TAM over the life cycle and facing major challenges such as natural disasters, climate changes, risk, uncertainty, and sustainability [113].

\subsubsection{Energy Harvesting}

Finally, the findings of the literature review identify potential research needs in energy harvesting systems or renewable energy sources, which may have impacts on the environmental vector of sustainability indicators. These have ramifications for social and economic vectors as well because such metrics rely on the population.

We indicated in Section 3.1 that, in terms of energy use, the LCT approach, namely through LCA studies, evaluates the environmental impacts of renewable energy sources' penetration into the micromobility system. However, the review of the literature suggests that big data and MaaS will rely on devices such as smartphones. Additionally, PMDs and intelligent transport systems, including active mobility modes, have been identified as being powered by batteries or using them to aid physical activity. Batteries charge relatively fast, and as a result of technological advances, powered micromobility arises [114]. Therefore, we present results from studies on vehicles powered by renewable sources or energy harvesting techniques from vehicle use.

Some energy generation or energy harvesting devices have been explored for energy recovery or smartphone powering. For instance, an energy harvester based on piezoelectric sensors aimed to produce small quantities of power from walking. Although the produced electric current was insufficient, researchers have pointed out an opportunity for future research to improve piezoelectric energy harvesting devices from a shoe [115]. An energy harvester that manages the foot slip demonstrated that it can generate enough power for wearable electronics [116]. Moreover, researchers recently addressed the design and 
feasibility of producing energy harvesting floors, highlighting their applicability to wireless sensors and IoT technologies. However, some problems, such as improving energy efficiency in both production and storage stages and adapting the floor displacement, were pointed to as research gaps $[117,118]$. For cycling, researchers also tested piezoelectric energy harvesting in a stationary exercise bicycle. It produced energy stored in a battery and with power enough to be used on sensors included on the bicycle [119].

Regardless of the source of energy, one of the most important issues is to increase the lifetime and energy efficiency of the batteries used in electrical PMDs. In this context, a new control methodology based on Fuzzy Logic Controllers (FLC) rather than Proportional Integral Derivative controllers (PID) has been proposed. When applied to an e-bike with a battery, this aims to consume the least amount of energy while remaining precise and flexible on error control. Preliminary results showed a $7-12 \%$ improvement in the energy management of the e-bike, implying a longer battery life. Future research on hybrid control strategies or the use of a neural network to train a fuzzy system needs evaluation so that more efficient models and longer battery lifetimes can emerge in the future [120].

From an economic point of view, a life cycle assessment of environmental and cost impacts shows that cargo bikes are the less pollutant and cheaper solution. However, these cover, on average, three times less distance than pollutant trucks, for a daily cost that is only $23 \%$. If the autonomy of batteries becomes longer and the purchase price of cargo bikes reduces, cargo bikes might become more cost-effective [59].

Such emerging research needs might be of interest regarding the perspective of the locations of e-scooter recharging stations. Unlike most of the literature studies calculating the optimal location and number of recharging stations, a recent study focused on calculating the energy consumption of e-scooters while seeking the cost-optimal solution for the locations and number of recharging stations given a specific number of trips. Previously, the literature was estimating the locations and number of recharging stations through distancebased energy consumption and therefore overestimating by $6 \%$ or underestimating by $30 \%$, which could lead to unnecessary and expensive stations or to micromobility vehicles running out of battery. Here, it depends on the energy management of the micromobility vehicles as well as the need for energy consumption. So, the indicated emerging research need is to consider the same model for larger-scale networks and for different recharging stations in terms of cost and charging speed [121].

\section{Discussion}

The presented literature review is an up-to-date collection of recent scientific work, highlighting significant contributions and research needs noted by many. First, we developed a meta-analysis using the VOSviewer software application. To detect the cooccurrence of authors or keywords, the software works with all bibliographical entries (inputs). We cite 520 distinct authors on the relevant themes in our review. At the same time, just 13 of them are quoted twice, with five of them being cited three times. Such a range confirms the topic's widespread interest among researchers all over the world.

Moreover, the intrinsic keywords of each article aid in analyzing the dominance of a few topics, among others. The presented literature review, as shown in Figure 5, focused on works around micromobility related to shared mobility, sustainability, life cycle assessment, safety, air pollution, and noise exposure. However, when applied to the micromobility context, security, the MaaS concept, and IoT are less-mentioned as keywords. The color bar enables us to examine the chronological distribution, which confirms that researchers have become more interested in the topic in recent years. Figure 5 shows the 29 most relevant keywords taken by the cited authors and used at least in two records. 


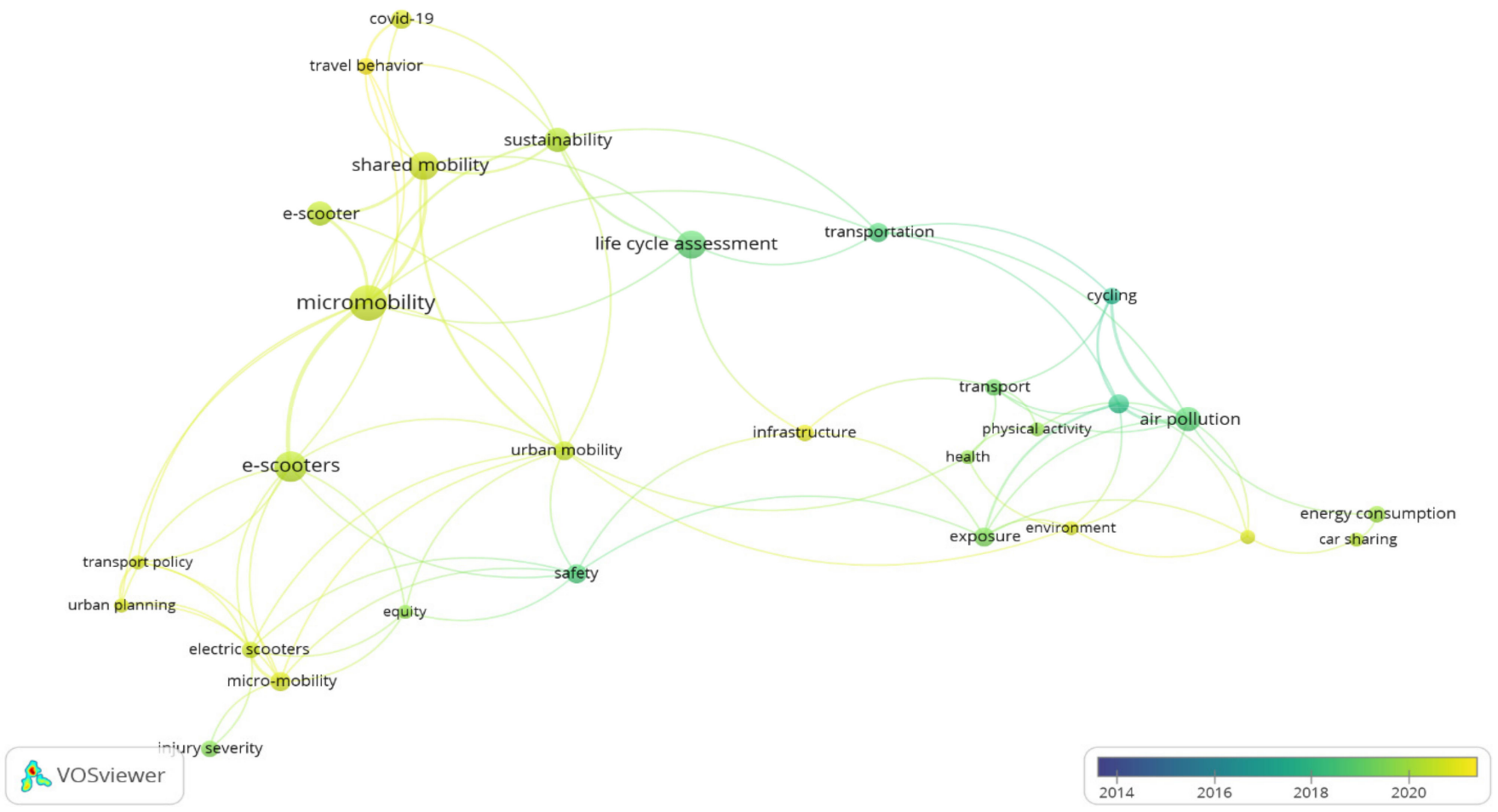

Figure 5. Visualization of the preponderance of each keyword considering co-occurrence and the publications' year.

In this section, we present our critical overview. Firstly, we present a glimpse of the bibliometric analysis performed on the 138 cited records (Figure 5). Secondly, we address the emerging R\&D areas for micromobility based on the results from the literature review, abovementioned in Section 3. The goal of this section is to emphasize the crucial emerging research needs and discuss a global system of thinking for incorporating them from the perspective of environmental, social, and economic sustainable integration. As a result, we propose a comprehensive integration framework based on an LCT approach applied to micromobility, emphasizing the connectivity between critical sectors, stakeholders, or research items.

\subsection{Emerging Research Opportunities}

From the previously presented literature review results, some emerging research needs around micromobility stand out. Starting from those that were significantly connected to the environmental appraisals (Section 3.1), the following list highlights the identified emerging opportunities:

- If any technological tool advised it, the majority of cyclists would consider adopting alternative paths to reduce pollution or noise exposure [35];

- Cities should plan infrastructures to promote active modes because the benefits of physical activity outweigh the risks [38]. Installing cycleways in streets with fewer vehicles, employing ventilation to disperse pollutants, and reducing obstacles such as bus stops and intersections are examples [39];

- Traffic-calming areas impact the air quality, and cyclists' exposure to pollution is yet inconclusive. Further experimental or modeling assessment is needed [39];

- Further research to re-evaluate the long-term risk-benefit balance of avoiding the use of PMDs in highly polluted periods is required, especially if considering patients with cardiovascular/respiratory diseases [45]; moreover, if modeling and simulation considers experimental data such as the obtained to see if mask usage prevents exposure effectively [46]; 
- The effects of cyclists' ventilation are still poorly considered. If they are not considered, cyclist's exposure is underestimated, hiding the effects of parameters such as slope, travel speed, wind, and other parameters to the exposure rate to pollutants [13];

- Modeling pedestrian exposure to comprise urban areas and pollutants with different characteristics while helping to define local strategies requires future research [42];

- Studies accounting for noise exposure are yet required, while the networks for measurement are still weak. Both might be convenient to any active mode [13];

- Governments have the onus to fund health and transport research regarding noise exposure affecting mode commuting in noisy urban areas. The disruptive environment should be researchers' goal, to inform policymakers on rapid changes [41];

- $\quad$ Estimating sustainability requires analyzing its three dimensions (environment, society, and economy). From the LCT perspective, studies to perform can be life cycle assessment (LCA), life cycle costing (LCC), social LCA, and life cycle sustainability assessment (LSCA) [52]. Integrated programs that combine LCA tools with other methodologies have the potential to assist in the evaluation of the urban complexity, particularly larger-scale systems such as mobility-related ones [50-52];

- Current analysis of environmental indicators results from LCA must include skepticism, while all the proposals available in a sensitivity analysis of references [49,53-59] result in emerging research opportunities to explore and re-evaluate, such as, for instance:

Considering the effects of replacing steel and aluminum with other materials such as bamboo [55,56];

Recycling aluminum using renewable energy to power the process [57,59];

Replacing trips performed by vans with trips performed by cargo bikes to locally replace the batteries of electrical PMDs [57,58];

$\checkmark \quad$ E-scooter providers and public transport should work on a joint and multimodal concept [53];

$\bigcirc \quad$ Quantifying more precisely the lifetime and PMD kilometers traveled to increase the accuracy of the LCA [53];

- To enable joint mobility systems is a chance for government policies, since merit-based business models, intelligent operation systems, and infrastructures are crucial for multimodal shared mobility [23].

Besides, mostly from records cited in Section 3.2 but also in the Introduction, we identify several other emerging opportunities of research regarding the inherent parallel research areas of micromobility. Table 1 provides an overview of the focus and contributions of the cited authors, as well as their suggestions for further research opportunities.

Table 1. Overview of the significant contributions of the cited works related to socio-economic dimensions.

\begin{tabular}{cccc}
\hline Topic & Reference & Major Findings and Contributions & $\begin{array}{c}\text { Future Work and Emerging } \\
\text { Opportunities }\end{array}$ \\
\hline $\begin{array}{c}\text { Personal mobility devices } \\
\text { Product development }\end{array}$ & {$[69]$} & $\begin{array}{c}\text { A new family of portable and inflatable } \\
\text { mobility devices with material and } \\
\text { design selection based on } \\
\text { environmental and injury concerns. }\end{array}$ & $\begin{array}{c}\text { Devices require long-term and } \\
\text { long-distance tests, stability analyses, } \\
\text { and newly designed technology to } \\
\text { freely control inflatable structure shape. }\end{array}$ \\
$\begin{array}{c}\text { Eco-Efficient Personal } \\
\text { Mobility Devices } \\
\text { Product development }\end{array}$ & {$[122]$} & $\begin{array}{c}\text { The proliferation of highly connected } \\
\text { personal and electric mobility vehicles } \\
\text { will contribute to reducing carbon } \\
\text { emissions and improving life quality. }\end{array}$ & $\begin{array}{c}\text { Micromobility vehicles are not yet } \\
\text { among the Cooperative Intelligent } \\
\text { Transport Systems. Required } \\
\text { connectivity opens a research niche, } \\
\text { including extensive data analysis. }\end{array}$ \\
\hline
\end{tabular}


Table 1. Cont.

\begin{tabular}{ccc}
\hline Topic & Reference & Major Findings and Contributions \\
\hline $\begin{array}{c}\text { Safety-Injury patterns and } \\
\text { Personal Mobility Devices }\end{array}$ & {$[4] \quad \begin{array}{c}\text { Significant health and financial costs to } \\
\text { the individual and society are born } \\
\text { from the prevalence of orthopedic } \\
\text { injuries coming from PMD usage. } \\
\text { Injury types are different from } \\
\text { motorcycle-related ones. }\end{array}$} \\
& \\
&
\end{tabular}

Literature review on road safety modeling finds neural networks as the

Safety-Road safety and crash prediction most used technique of ML. The article explores three different ML approaches to predict crashes and promote safe mobility.

Identifies the potential attacks to security, safety, and privacy of active

Security and Privacy Challenges; users: physical damage, eavesdropping, man in the middle and replay attacks, fuzzing and denial of service, spoofing, user data sharing, and inference.

\section{Future Work and Emerging} Opportunities

Suggests future work on injury patterns, new protective gear associated costs, strict regulations on PMD impacts, awareness actions, safety measures, and accident consequences.

Models will benefit from more significant amounts of data, especially if using new exploratory variables, different from road-environmental, vehicle-related, or human factors and crash traits.

The article suggests countermeasures: service providers should give non-riders/other users the chance to report issues/errors.

Applications/servers should prevent data leakages with updates and by regularly monitoring/filtering real-time traffic.

Ridership mapping, attitude tracking, and safety assessment using crowdsourced data to fill gaps of R\&D. Big Data [22] Enormous power and data amounts will come from bicycling. Based on prior work, the authors point out the issues of big data.

The study presents an estimation method on e-scooter flow. Data care of millions of entries regarding

Big Data [3] start/finish points of trips using PMDs (e-scooters) supports city planning.

Through a first joint simulation of carsharing, bike-sharing, and ride-hailing, MATsim assesses the MaaS [20] impacts of shared modes on MaaS. For

Zurich, transport-related energy consumption can reduce between 25 and $43 \%$

Signs related to a mindset of demand for multimodal mobility solutions, including novelty, freedom, and new MaaS [105] tools, are judged to find early adopters of MaaS, so that involved parts learn
Concerns with big data are access and funding, privacy, representativeness and equity, analytics and data uncertainty, open methods, and stakeholder capacity. People's engagement in sharing data, stories, and experiences may help politicians.

To develop systems that inform stakeholders/researchers on the paths taken, creating even more extensive data sets free of privacy attacks might enhance the built method for better policy proposals.

The new context of public transport, including innovative shared modes, may solve demand/supply issues. Simulation with shared Mobility and MaaS can be scaled up and avoid minor bias on existing partial models.

Recommends identifying which types of trip suits MaaS the most, including micromobility. To clarify how MaaS can be widely adopted is also suggested. users' traits. 
Table 1. Cont.

\begin{tabular}{|c|c|c|c|}
\hline Topic & Reference & Major Findings and Contributions & $\begin{array}{c}\text { Future Work and Emerging } \\
\text { Opportunities }\end{array}$ \\
\hline Energy Harvesting & [119] & $\begin{array}{l}\text { The pilot device involves the } \\
\text { conversion of a bicycle into a stationary } \\
\text { exercise bike with a piezoelectric } \\
\text { generator. The energy harvesting } \\
\text { system used in bicycles shows the } \\
\text { potential to provide low-power } \\
\text { equipment with renewable energy } \\
\text { sources. }\end{array}$ & $\begin{array}{l}\text { Further research is needed to improve } \\
\text { the energy harvesting system's } \\
\text { efficiency by adding more piezoelectric } \\
\text { modules. It identifies a research } \\
\text { opportunity to confirm energy } \\
\text { harvesting systems' potential to power } \\
\text { IoT-related devices. }\end{array}$ \\
\hline $\begin{array}{l}\text { Micromobility and Public } \\
\text { Transport integration. }\end{array}$ & [123] & $\begin{array}{l}\text { Findings show the potential of shared } \\
\text { e-mobility (mainly used for short trips) } \\
\text { to enable rising mobility services. } \\
\text { Moreover, it concludes that the demand } \\
\text { for diverse modes shares many } \\
\text { common predictors. }\end{array}$ & $\begin{array}{l}\text { Opportunity identified on topics earlier } \\
\text { reviewed for other transport modes but } \\
\text { not yet for shared e-mobility such as } \\
\text { the type of service to provide for } \\
\text { micromobility regarding the trip type. }\end{array}$ \\
\hline $\begin{array}{l}\text { Micromobility and Public } \\
\text { Transport integration. }\end{array}$ & [18] & $\begin{array}{l}\text { The study of e-scooters mixing in ten } \\
\text { big cities proves their attractiveness as } \\
\text { urban transport modes. Space, speed, } \\
\text { or safety conflicts are due to poor plans } \\
\text { and stress the need to boost transport } \\
\text { infrastructures or drop other vehicles' } \\
\text { speed. }\end{array}$ & $\begin{array}{l}\text { Research gap identified regarding the } \\
\text { clarification of trip goals. It is currently } \\
\text { unclear whether e-scooters create } \\
\text { additional transport demand or if they } \\
\text { replace trips. Injury types or accident } \\
\text { rates require classification. }\end{array}$ \\
\hline $\begin{array}{l}\text { Micromobility and Public } \\
\text { Transport integration. }\end{array}$ & [2] & $\begin{array}{l}\text { Literature review of studies focused on } \\
\text { the integration of micromobility and } \\
\text { public transport. It assesses the current } \\
\text { state of knowledge and provides an } \\
\text { overview of recommendations, while } \\
\text { e-micro-vehicles are yet to be studied. }\end{array}$ & $\begin{array}{l}\text { Main gaps relate to the clarification of } \\
\text { the benefits and limitations of mixing } \\
\text { modes concerning socio-economic and } \\
\text { ecological values. Clarification of } \\
\text { whether micromobility serves as } \\
\text { access/egress to public modes requires } \\
\text { data analysis. }\end{array}$ \\
\hline
\end{tabular}

Furthermore, based on the literature review around product development, one emerging research area is the need to produce more ergonomically friendly PMDs that do not cause orthopedic injuries from long-term usage. The electrification of PMDs, on the other hand, will increase the average speed of micromobility vehicles on the streets. That implies that progress in the crashes' prevention or detection through digitalization, IoT, or ML application to the vehicle itself is not the only action. Individual safety devices such as helmets are also among the emerging R\&D areas in terms of improved ergonomics during their use and guaranteed safety in the event of an accident. Such assessment, sustainable material selection, and manufacturing processes highlight the engineering perspective required for the desirably sustainable integration of micromobility. Moreover, digitalization relates to the possibility of integrating cargo bikes into fleet management systems, so to develop ones able to use communication tools will be a vital emerging need to tackle [70]. Moreover, creating new protective gear that provides the same or greater level of protection while remaining sustainable and cost-effective is an upcoming challenge.

In terms of security issues, research has revealed that users are concerned about the likelihood of attacks on their personal and financial data, emphasizing the importance of avoiding data leakages. In addition, from the standpoint of the vehicles, an emerging research opportunity stands out from the necessity to develop cryptographic solutions, which necessarily rely on programming safer apps for service providers. While such countermeasures to malicious attacks increase the security of micromobility, they also function as accident prevention, which provides chances for safety-related improvements. These may be used in conjunction with ML algorithms and secure data gathering to describe PMD-related crashes in order to better understand the safety issues before addressing them 
with appropriate solutions. According to the literature review, users will gain trust and feel more secure and safer if data is collected to characterize their paths and potential crashes or injuries, more than they would if merely collecting the start and end points of the micromobility trips, especially if it would not jeopardize crucial players' security. As a result, examining the usage patterns of micromobility vehicles would be of significant interest [124].

Likewise, while pedestrians are concerned about their safety and with the issue of improperly parked dockless micromobility vehicles, it is vital to penetrate into the general public with laws from local governments which have not been verified yet, according to James et al. [86]. However, their work does not mention the use of operational services that can be used to collect dumped e-scooters. This sets up an emerging area of intervention where geolocation, digitization, data sharing, and legislation and policies will need to be aligned to clear the sidewalks of undue obstacles. Even more so from the life cycle thinking viewpoint if we consider that the sustainability impacts from environmental, social, and economic causes are highly related to this collaboration. If operational services remove dumped micromobility vehicles from sidewalks, this has a social impact through increased safety. However, the life cycle impacts to the environment and to the businesses will depend as well on what type of vehicle will be used to perform the collection. It can be, for instance, a fuel-powered truck or an electric one, which means different long-term impacts in the full range of sustainability.

Additionally, the connectivity between mobility modes in a smart and eco-efficient city should enable a new set of innovative hardware and software tools, such as those from the IoT [122]. Moreover, many countries lack adequate infrastructure to meet micromobility criteria if MaaS is to replace private cars with public transport and active modes [125]. As a result, three activities will be essential to determine whether micromobility is appropriate for the MaaS application: the evaluation of demand patterns (mode substitution or new trips), the classification of injury and accident types, and the elucidation of the socio-economic-ecological cost-benefit ratios. These will assist in clarifying how micromobility interacts with public transport. Moreover, it will be crucial to consider the cost-effectiveness of replacing trips performed by car. For that, the seasonality effects, personal preference/aversion toward new micromobility options, or the effects of specific revenue models should be considered to evaluate which is the optimum number of vehicles in a fleet of shared mobility services [111]. Recently, a floating car data analysis has shown that about $22 \%$ of car trips are potentially replaceable by micromobility vehicles, however, this study still lacks in considering the interaction of PMDs with other transport modes and accessibility to public transport. With a more complete data analysis, estimations of the potential demand for micromobility vehicles will be more precise and, therefore, the design of a possible network for these vehicles will be more accurate [126].

From the energy point of view, research recommendations show that energy management, once stored through efficient control, is critical in addressing the anticipated environmental issues hypothetically generated by batteries. So, the predicted trends are upgrades to lithium-ion batteries to lower the $95 \%$ of e-bikes in China that use lead-acid ones and to ensure that their lifetime is longer while employing renewable sources of energy such as solar, piezoelectric, and others [127]. Changeable battery packs, as well as more efficient and longer-life batteries, might contribute to solving the problem of collecting e-scooters each night and returning them to the streets around the clock. For instance, Lime scooters had to be collected while Neuron's-designed with changeable battery packs-do not. This could mean that different city governments should be ready to harness such novelties and rethink how we plan and govern cities [128]. Moreover, LCA studies of the lithium-ion batteries used in vehicles could include more complete material inventories to fill research gaps in environmental LCAs of energy storage systems [129]. Likewise, in a life-cycle cost analysis, the operational services may be less detrimental to the cost/benefit ratio. If they are less needed, together with the electric cargo bikes hopefully covering more trips performed by vans and using smaller and lighter parcels, a more sustainable shared 
mobility business could be achieved in the future [58]. That improvement would ensure the economic sustainability dimension while the penetration of renewables would ensure the boost in environmental sustainability [59]. As is once again evidenced, the importance of interoperability between emerging research needs for changeable and longer-life batteries without affecting the life-cycle cost analysis and the possible need for more or a smaller number of trips performed by the operational services (potentially expensive and pollutant) provided by the shared-mobility companies to collect the dumped vehicles.

The use of parcels for logistics and last-mile deliveries will inevitably include costs that can be estimated and compared with other vehicles following a methodology that accounts for the external and internal costs to promote a rational response for urban planners. Each city could preliminarily adapt its characteristics to the needs of urban freight systems and select the best PMD for last-mile deliveries if using such methodology [130]. If such a methodology is applied, city planners will need to regulate the traffic of freight micromobility vehicles, ideally in co-operation with freight operators which will require the assessment of social costs. That regulation could be differentiated regarding each type of vehicle and could have multiple economic impacts on the operators if it stands only by the idea of prohibiting instead of no constraints except to apply sanctions [131].

Finally, a particular example of the integration of different emerging research needs through a life cycle thinking approach was found. Regarding the energy harvesting systems, it was found to be an emerging research need to seek more efficient piezoelectric systems to store more electricity, for example in a bicycle battery $[117,118]$. Likewise, recharging stations with solar panels could be evaluated with new shapes and designs as well as extendable surfaces [132]. Such could mean more expensive lifetime solutions, thus potentially compromising the cost-effectiveness of new micromobility solutions. However, the presented model [121] for the calculation of the number and location of recharging stations can be used to determine if policymakers can decide to use a smaller number for the same space and number of trips of an e-scooter. Such a model has yet to be tested for largerscale networks. In any case, if an energy harvester becomes more efficient it may result in an e-scooter or bicycle needing less energy from the recharging stations to travel the same distances. The same recharging station might be more effective from the perspective of costs and environmental issues if using solar panels efficiently. Thus, the economic sustainability of micromobility might arrive in the world from the integration with a technological breakthrough as well as with socially and environmentally sustainable impacts. In this way, life cycle sustainable integration could be fulfilled over its three dimensions.

\subsection{Comprehensive Integration through an LCT Approach: Connecting the Research Dots}

The results revealed that the emerging research areas and technological developments in micromobility will continue to be linked to PMDs, cargo bikes, or inherently related topics. Commonly, the scientific community identified the impacts of (shared) micromobility as increased mobility ratios and health benefits, reduced GHG emissions, and decreased automobile use [133]. However, relying solely on the most recent advances in information technology and ownership desires will not make this integration into cities more sustainable [134].

Also, in LCA studies such as the one developed by Hollingsworth et al., the creation of an indicator capable of integrating the carbon footprint and carbon handprint is not included, and nor is the user's comfort and safety [49]. Such integration is supported by a number of parallel research areas with socio-economic impacts, such as those regarding the safety perceptions of pedestrians and electrical scooter users [135]. Thus, the long-term integration of micromobility is far denser than just focusing on environmental concerns.

Therefore, in Figure 6, we propose a conceptual framework for how multiple environmental and socioeconomic sectors can work together to meet the mobility needs of the population by resorting to micromobility modes, emphasizing the goal for sustainability, and promoting a comprehensive LCT approach. Its goal is to spark the discussion about 
how business models can be adapted to include shared (micro)mobility with PMDs and achieve the opportunities identified in Section 4.1.

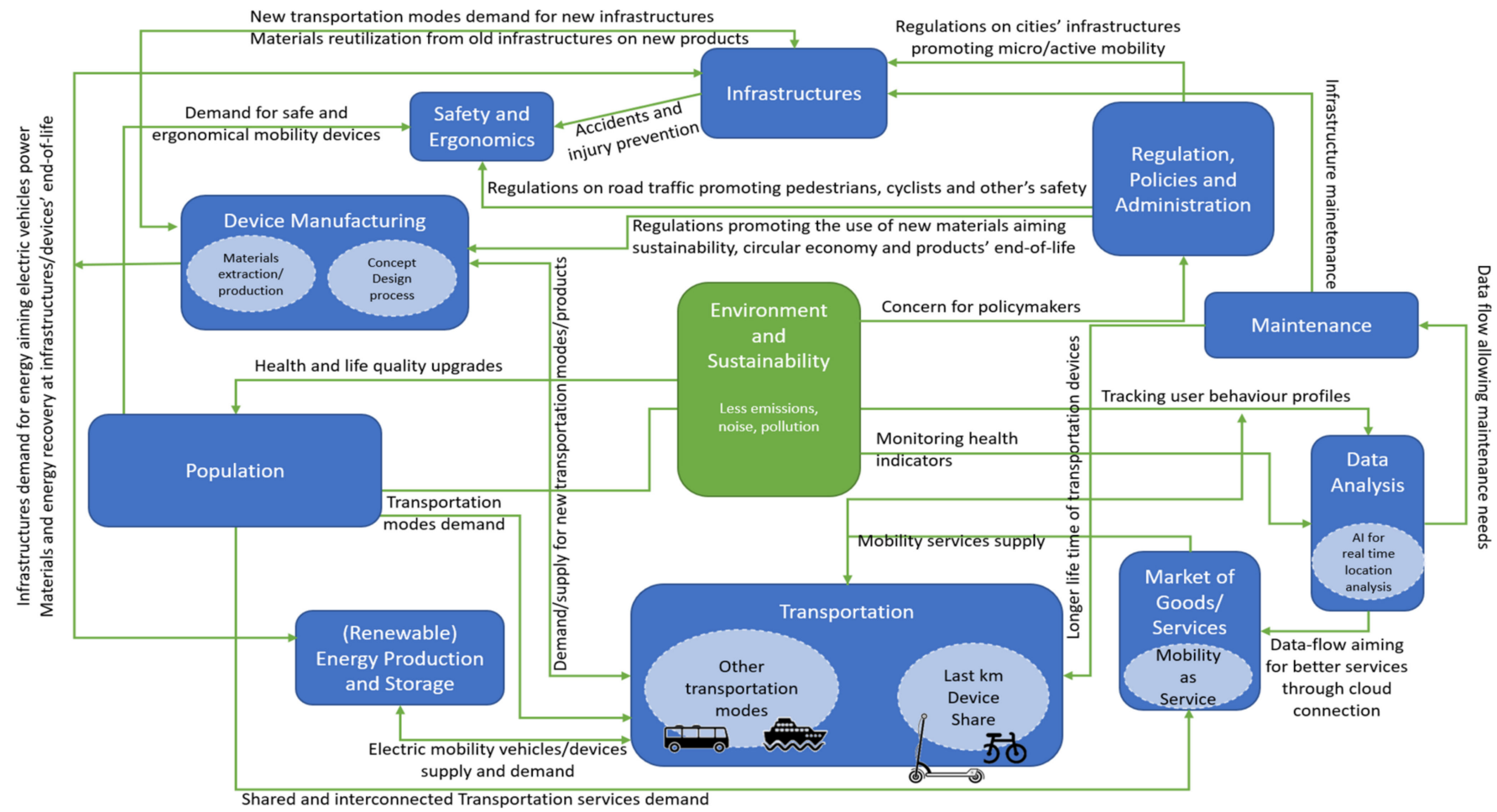

Figure 6. A framework of comprehensive integration through an LCT approach applied to micromobility modes.

Figure 6 is a proposal of a conceptual framework of a comprehensive integration between research areas through an LCT approach applied to micromobility modes. It is inspired by one major research opportunity identified in Section 4.1: estimating sustainability requires analyzing its three dimensions (environment, society, and economy). Likewise, it follows the work performed by peer authors who proposed the conceptualization of the environmental effects of carsharing. Their and our proposals both address concerns about integrating the population requiring PMDs manufacturing [136]. Such population demand is unavoidable as they seek not only devices manufactured through environmentally friendly processes but also safe and ergonomic devices. Likewise, the population that uses these modes calls for improvements in health and environmental indicators. According to our literature review, this can be addressed by conducting LCA studies as well as complementary noise and pollution exposure studies. LCA's GHG emissions and energy consumption indicators require the filling of a research gap with noise and pollution exposure studies. Moreover, our vision of an LCT approach for micromobility includes the topic of possible improvements related to renewable energy sources.

The framework also builds from peer re-evaluation work on the LCA to promote the sustainable re-use of resources, materials, and energy, particularly from the end-of-life of infrastructures for new vehicles [137]. It confirms, for instance, the importance of including pavement and infrastructural developments in LCA studies, given their importance to sustainability improvement. Not only in the environmental dimension but on the business side as well, the costs are more beneficial if paid "up-front" when looking for a costeffective life-cycle micromobility system. For example, in the transportation sector, LCC will be key to selecting the right combination between pavement types for micromobility vehicles. However, the impacts of using LCC techniques toward this goal are yet to be fully recognized and the benefits of applying LCC are not yet clearly observed in practice. 
If such a gap between theory and practice is filled, LCC for transportation projects will support the decisions of the public and policymakers in the long run [138].

Moreover, based on our analysis of the literature review findings, we believe that big data analysis is critical. If secure data-sharing methods promote the tracking of paths taken, micromobility users will serve as data producers. Likewise, the development of research on big data will not only support the MaaS concept foundation with micromobility, but it will also assist the maintenance needs, advise on the appropriate policies, and promote the development of sustainable business models including modern, sustainable, and digitalized cargo bikes. As a result, the socioeconomic sectors associated with vehicle and infrastructure maintenance are also included in this LCT approach. Finally, we emphasize the government's responsibility to fund health and transport research. At the same time, we recognize the need for road traffic management and infrastructure regulations in cities so that micromobility sustainable integration can continue.

Hence, our literature review reveals a shift in government policies to enable joint mobility systems. Additionally, merit-based business models, intelligent operation systems, and infrastructures are critical for multimodal shared mobility. Moreover, it shows that integrated programs that combine LCA tools with other methodologies can aid in assessing urban complexity. Particularly for larger-scale systems such as mobility-related systems. Therefore, our comprehensive integration framework based on an LCT approach applied to PMDs serves as a roadmap for the quest to implement a fully sustainable micromobility system, and it summarizes the interconnectivity between all the researched topics.

\section{Conclusions}

Our literature review covers an extensive database of scientific work on the topic of micromobility. By restricting the cited texts primarily to documents from the last seven years, our work has managed to provide an up-to-date overview of the recent trends followed by our peers. It provides a solid foundation for understanding the current state of micromobility transport system implementation. Either by highlighting emerging research opportunities or by advising on the aggregated ways of thinking that will underpin future decision-makers' actions.

In conclusion, based on the literature review, micromobility is headed for a future with increased environmental sustainability and decreased injury risk. It will include portable and inflatable mobility devices made of new materials and better-designed shapes. Furthermore, if the measures identified in the sensitivity analysis of LCA studies are implemented, it will include micromobility vehicles with lower GHG emissions per passenger-kilometer. Additionally, the health benefits of physical activity increase, and the pollution drop is greater than the risks of particle exposure. So, once the noise reduction is established, the efficient use of PMDs will demonstrate the potential to induce environmental improvements during the use phase, particularly if the user switches from a motor vehicle to a PMD. Thus, we conclude that the typical results in terms of environmental indicators coming from LCA can be complemented with the results of studies on user exposure to noise and pollutant emissions. Similarly, we conclude that if the scientific community fills the research gaps identified for the social sector, micromobility users will feel safer and more engaged with related modes. Among these are the precise definition of security challenges that must be addressed, as well as the need for modeling and predicting road safety, users' behavior, and crashes.

However, our review of the literature confirms that the significant research opportunities associated with micromobility systems depend on the government's ability to fund health and transport research. Similarly, it demonstrates that providers of micromobility services and public transport should collaborate on a joint concept so that these transport modes can complement one another. Moreover, our research shows that the disruptive environment should be the researchers' goal, with the goal of integrating LCT techniques and other methodologies as well as sectors such as social and economic sectors. 
One of the many examples of the relationship between research breakthroughs on the addressed topics is, for example, that the life-cycle cost analysis of a micromobility vehicle might even include the costs associated with the need for recharging stations in cities. Our work shows that there is an emerging research need to study a model for calculating their location and required number in larger networks and larger cities. Such can guarantee improvements in the economic long-term sustainability of micromobility. However, its full potential will only be achieved if we find ways of introducing energy harvesters to reduce the energy consumption of micromobility vehicles under social cost-effectiveness. Moreover, the clean energy used in recharging stations must guarantee environmental sustainability in the long term. These are the kind of findings that support our perspective that any emerging research needs related to micromobility will be impactful if tackled from the perspective of an aggregating life cycle thinking approach. In other words, for any micromobility project-based life cycle analysis, assessing the impacts of tackling one of the identified emerging research needs is crucial before and after implementation to guarantee sustainability.

As a result, the findings of our literature review support our proposal for a comprehensive integration of research needs from an LCT perspective based on our framework figure. From that, we conclude that the introduction of micromobility into the world will be socially, economically, and environmentally sustainable only if a multi-sectoral perspective and way of thinking are enabled. Further research in micromobility should focus on the interoperability of sectors such as demanding populations, device manufacturing, infrastructures, maintenance, safety, security, ergonomics, renewable energy sources, big data analysis, and MaaS. These should be complementary to the environmental-related indicators, forming the previously mentioned joint concept. Otherwise, sustainability in its entirety cannot be guaranteed, and a micromobility transport system cannot be considered a viable replacement for polluting vehicles. Even if LCA indicators (GHG emissions and energy consumption) suggest it, the business models and social acceptance must be considered for micromobility to be accepted in the long term as sustainable.

Author Contributions: Conceptualization, D.L.M. and M.C.C.; Methodology, D.L.M. and M.C.C.; Investigation, D.L.M.; Writing-Original Draft Preparation, D.L.M.; Writing-Review and Editing, D.L.M. and M.C.C.; Supervision, M.C.C.; Project Administration, M.C.C.; Funding Acquisition, M.C.C. All authors have read and agreed to the published version of the manuscript.

Funding: This paper was funded by the Research Package "Life Cycle Thinking of Active MobilityFrom the Concept to the Use, under a Mechanical Technology and Automation Perspective" from the mobilizing project "Technologies for the wellbeing" aligned with Strategic Plan 2018-2022 of Centre for Mechanical Technology and Automation (TEMA)-University of Aveiro, under projects UIDB/00481/2020 and UIDP/00481/2020—Fundação para a Ciência e a Tecnologia; and CENTRO01-0145-FEDER-022083 - Centro Portugal Regional Operational Programme (Centro2020), under the PORTUGAL 2020 Partnership Agreement, through the European Regional Development Fund.

Institutional Review Board Statement: Not applicable.

Informed Consent Statement: Not applicable.

Data Availability Statement: Not applicable.

Conflicts of Interest: The authors declare no conflict of interest. The authors of this critical literature review do not have any kind of conflicts of interest with any other scientific institution or researcher. The funding sponsors had no role in the design of the study; in the collection, analyses, or interpretation of data; in the writing of the manuscript; and in the decision to publish the results. 


\section{References}

1. Stark, J.; Meschik, M.; Singleton, P.A.; Schützhofer, B. Active school travel, attitudes and psychological well-being of children. Transp. Res. Part F Traffic Psychol. Behav. 2018, 56, 453-465. [CrossRef]

2. Oeschger, G.; Carroll, P.; Caulfield, B. Micromobility and public transport integration: The current state of knowledge. Transp. Res. Part D Transp. Environ. 2020, 89, 102628. [CrossRef]

3. Feng, C.; Jiao, J.; Wang, H. Estimating E-Scooter Traffic Flow Using Big Data to Support Planning for Micromobility. J. Urban Technol. 2020, 1-19. [CrossRef]

4. Ang, K.X.M.; Chandrakumara, S.D.; King, C.K.K.; Loh, S.Y.J. The Orthopedic Injury Burden of Personal Mobility Devices in Singapore-Our Experience in the East Coast. J. Clin. Orthop. Trauma 2020, 13, 66-69. [CrossRef] [PubMed]

5. Møller, T.H.; Simlett, J. Micromobility: Moving Cities into a Sustainable Future. Available online: https://assets.ey.com/content/ dam/ey-sites/ey-com/en_gl/topics/automotive-and-transportation/automotive-transportation-pdfs/ey-micromobilitymoving-cities-into-a-sustainable-future.pdf (accessed on 13 October 2021).

6. Galatoulas, N.-F.; Genikomsakis, K.N.; Ioakimidis, C.S. Spatio-Temporal Trends of E-Bike Sharing System Deployment: A Review in Europe, North America and Asia. Sustainability 2020, 12, 4611. [CrossRef]

7. The Meddin Bike-Sharing World Map Mid-2021 Report. Available online: https://bikesharingworldmap.com/reports/bswm_ mid2021report.pdf (accessed on 13 October 2021).

8. Meddin, R.; DeMaio, P.J. The Meddin Bike-Sharing World Map. Available online: https://bikesharingworldmap.com/\#/all/2.3/ 8.06/54.59/\%0A;https:/ / bikesharingworldmap.com/\#/all/2.3/-1.57/33.92/\%0A;https:/ /bikesharingworldmap.com/\#/all/ $6.9 /-72.01 / 19.73 /$ (accessed on 13 October 2021).

9. POLIS Macro Managing Micro Mobility. Available online: https://www.polisnetwork.eu/wp-content/uploads/2019/11/PolisPaper-Macromanaging-MicroMobility.pdf (accessed on 13 October 2021).

10. MDCG DocsRoom-European Commission. Ongoing MDR IVDR Guidance Plan. 2020. Available online: https:/ / ec.europa.eu/ docsroom/documents/37824 (accessed on 28 March 2021).

11. McQueen, M.; Abou-Zeid, G.; MacArthur, J.; Clifton, K. Transportation Transformation: Is Micromobility Making a Macro Impact on Sustainability? J. Plan. Lit. 2020, 36, 46-61. [CrossRef]

12. de Bortoli, A.; Christoforou, Z. Consequential LCA for territorial and multimodal transportation policies: Method and application to the free-floating e-scooter disruption in Paris. J. Clean. Prod. 2020, 273, 122898. [CrossRef]

13. Gelb, J.; Apparicio, P. Cyclists' exposure to atmospheric and noise pollution: A systematic literature review. Transp. Rev. 2021, 41, 742-765. [CrossRef]

14. Wolf, A.; Seebauer, S. Technology adoption of electric bicycles: A survey among early adopters. Transp. Res. Part A Policy Pract. 2014, 69, 196-211. [CrossRef]

15. Castro, A.; Gaupp-Berghausen, M.; Dons, E.; Standaert, A.; Laeremans, M.; Clark, A.; Anaya-Boig, E.; Cole-Hunter, T.; AvilaPalencia, I.; Rojas-Rueda, D.; et al. Physical activity of electric bicycle users compared to conventional bicycle users and non-cyclists: Insights based on health and transport data from an online survey in seven European cities. Transp. Res. Interdiscip. Perspect. 2019, 1, 100017. [CrossRef]

16. Cazzola, P.; Crist, P. Good to Go? Assessing the Environmental Performance of New Mobility. Available online: https://www.itfoecd.org/good-go-assessing-environmental-performance-new-mobility (accessed on 20 July 2021).

17. de Bortoli, A. Environmental performance of shared micromobility and personal alternatives using integrated modal LCA. Transp Res. Part D Transp. Environ. 2021, 93, 102743. [CrossRef]

18. Gössling, S. Integrating e-scooters in urban transportation: Problems, policies, and the prospect of system change. Transp. Res. Part D Transp. Environ. 2020, 79, 102230. [CrossRef]

19. Vinayaga-Sureshkanth, N.; Wijewickrama, R.; Maiti, A.; Jadliwala, M. Security and Privacy Challenges in Upcoming Intelligent Urban Micromobility Transportation Systems. In Proceedings of the Second ACM Workshop on Automotive and Aerial Vehicle Security, New Orleans, LA, USA, 18 March 2020; ACM: New York, NY, USA, 2020; pp. 31-35.

20. Becker, H.; Balac, M.; Ciari, F.; Axhausen, K.W. Assessing the welfare impacts of Shared Mobility and Mobility as a Service (MaaS). Transp. Res. Part A Policy Pract. 2019, 131, 228-243. [CrossRef]

21. Zhang, H.; Song, X.; Xia, T.; Zheng, J.; Haung, D.; Shibasaki, R.; Yan, Y.; Liang, Y. MaaS in Bike-Sharing: Smart Phone GPS Data Based Layout Optimization and Emission Reduction Potential Analysis. Energy Procedia 2018, 152, 649-654. [CrossRef]

22. Nelson, T.; Ferster, C.; Laberee, K.; Fuller, D.; Winters, M. Crowdsourced data for bicycling research and practice. Transp. Rev. 2020, 41, 97-114. [CrossRef]

23. Meng, L.; Somenahalli, S.; Berry, S. Policy implementation of multi-modal (shared) mobility: Review of a supply-demand value proposition canvas. Transp. Rev. 2020, 40, 670-684. [CrossRef]

24. Rose, G. E-bikes and urban transportation: Emerging issues and unresolved questions. Transportation 2012, 39, 81-96. [CrossRef]

25. O'Hern, S.; Estgfaeller, N. A Scientometric Review of Powered Micromobility. Sustainability 2020, 12, 9505. [CrossRef]

26. Abduljabbar, R.L.; Liyanage, S.; Dia, H. The role of micro-mobility in shaping sustainable cities: A systematic literature review. Transp. Res. Part D Transp. Environ. 2021, 92, 102734. [CrossRef]

27. Chang, A.Y.; Miranda-Moreno, L.; Clewlow, R.; Sun, L. Trend or Fad. Available online: https:/ / www.sae.org/micromobilityreport (accessed on 13 October 2021). 
28. ITF Safe Micromobility CPB Report. Available online: https://www.itf-oecd.org/safe-micromobility (accessed on 12 October 2021).

29. Mendeley Search. Available online: https://www.mendeley.com/search/ (accessed on 13 October 2021).

30. Web of Science Document Search-Web of Science Core Collection. Available online: https://www.webofscience.com/wos/ woscc/basic-search (accessed on 13 October 2021).

31. Scopus-Document Search. Available online: https://www.scopus.com/search/form.uri?display=basic\#basic (accessed on 8 October 2021).

32. ScienceDirect.com. Science, Health and Medical Journals, Full Text Articles and Books. Available online: https://www. sciencedirect.com/ (accessed on 8 October 2021).

33. Centre for Science and Technology Studies. VOSviewer: Visualizing Scientific Landscapes. Available online: https://www. vosviewer.com/ (accessed on 13 October 2021).

34. Committee on the Medical Effects of Air Pollutants. Review of the UK Air Quality Index; Government of the United Kingdom: Lonodon, UK, 2011; Volume 66, ISBN 9780859516990. Available online: https:/ / assets.publishing.service.gov.uk/government/ uploads/system/uploads/attachment_data/file/304633/COMEAP_review_of_the_uk_air_quality_index.pdf (accessed on 13 October 2021).

35. Ueberham, M.; Schlink, U.; Dijst, M.; Weiland, U. Cyclists' Multiple Environmental Urban Exposures-Comparing Subjective and Objective Measurements. Sustainability 2019, 11, 1412. [CrossRef]

36. Apparicio, P.; Carrier, M.; Gelb, J.; Séguin, A.-M.; Kingham, S. Cyclists' exposure to air pollution and road traffic noise in central city neighbourhoods of Montreal. J. Transp. Geogr. 2016, 57, 63-69. [CrossRef]

37. Apparicio, P.; Gelb, J.; Carrier, M.; Mathieu, M.; Kingham, S. Exposure to noise and air pollution by mode of transportation during rush hours in Montreal. J. Transp. Geogr. 2018, 70, 182-192. [CrossRef]

38. Okokon, E.O.; Yli-Tuomi, T.; Turunen, A.W.; Taimisto, P.; Pennanen, A.; Vouitsis, I.; Samaras, Z.; Voogt, M.; Keuken, M.; Lanki, T. Particulates and noise exposure during bicycle, bus and car commuting: A study in three European cities. Environ. Res. 2017, 154, 181-189. [CrossRef] [PubMed]

39. Krecl, P.; Cipoli, Y.A.; Targino, A.C.; Castro, L.B.; Gidhagen, L.; Malucelli, F.; Wolf, A. Cyclists' exposure to air pollution under different traffic management strategies. Sci. Total Environ. 2020, 723, 138043. [CrossRef]

40. Fernandes, P.; Vilaça, M.; Macedo, E.; Sampaio, C.; Bahmankhah, B.; Bandeira, J.; Guarnaccia, C.; Rafael, S.; Relvas, H.; Borrego, C.; et al. Integrating road traffic externalities through a sustainability indicator. Sci. Total Environ. 2019, 691, 483-498. [CrossRef] [PubMed]

41. Giles-Corti, B.; Zapata-Diomedi, B.; Jafari, A.; Both, A.; Gunn, L. Could smart research ensure healthy people in disrupted cities? J. Transp. Health 2020, 19, 100931. [CrossRef]

42. Santiago, J.; Borge, R.; Sanchez, B.; Quaassdorff, C.; de la Paz, D.; Martilli, A.; Rivas, E.; Martín, F. Estimates of pedestrian exposure to atmospheric pollution using high-resolution modelling in a real traffic hot-spot. Sci. Total Environ. 2020, 755, 142475. [CrossRef]

43. Schmid, D.; Ricci, C.; Leitzmann, M.F. Associations of Objectively Assessed Physical Activity and Sedentary Time with All-Cause Mortality in US Adults: The NHANES Study. PLoS ONE 2015, 10, e0119591. [CrossRef] [PubMed]

44. Burnett, R.; Chen, H.; Szyszkowicz, M.; Fann, N.; Hubbell, B.; Pope, C.A., III; Apte, J.S.; Brauer, M.; Cohen, A.; Weichenthal, S.; et al. Global estimates of mortality associated with long-term exposure to outdoor fine particulate matter. Proc. Natl. Acad. Sci. USA 2018, 115, 9592-9597. [CrossRef]

45. Giallouros, G.; Kouis, P.; Papatheodorou, S.I.; Woodcock, J.; Tainio, M. The long-term impact of restricting cycling and walking during high air pollution days on all-cause mortality: Health impact Assessment study. Environ. Int. 2020, 140, 105679. [CrossRef]

46. Cherrie, J.W.; Apsley, A.; Cowie, H.; Steinle, S.; Mueller, W.; Lin, C.; Horwell, C.J.; Sleeuwenhoek, A.; Loh, M. Effectiveness of face masks used to protect Beijing residents against particulate air pollution. Occup. Environ. Med. 2018, 75, 446-452. [CrossRef] [PubMed]

47. Marinelli, S.; Lolli, F.; Gamberini, R.; Rimini, B. Life Cycle Thinking (LCT) applied to residential heat pump systems: A critical review. Energy Build. 2019, 185, 210-223. [CrossRef]

48. Hauschild, M.Z.; Rosenbaum, R.K.; Stig, I.O. Life Cycle Assessment: Theory and Practice; Springer International Publishing: New York, NY, USA, 2014; ISBN 9781315778730.

49. Hollingsworth, J.; Copeland, B.; Johnson, J.X. Are e-scooters polluters? The environmental impacts of shared dockless electric scooters. Environ. Res. Lett. 2019, 14, 084031. [CrossRef]

50. Onat, N.C.; Kucukvar, M.; Halog, A.; Cloutier, S. Systems Thinking for Life Cycle Sustainability Assessment: A Review of Recent Developments, Applications, and Future Perspectives. Sustainability 2017, 9, 706. [CrossRef]

51. Senitkova, I.; Bednářová, P. Life Cycle Assessment. JP J. Heat Mass Transf. 2015, 11, 29-42. [CrossRef]

52. Boix, A.P.; Llorach-Massana, P.; Sanjuan-Delmás, D.; Sierra-Pérez, J.; Vinyes, E.; Gabarrell, X.; Rieradevall, J.; Sanyé-Mengual, E. Application of life cycle thinking towards sustainable cities: A review. J. Clean. Prod. 2017, 166, 939-951. [CrossRef]

53. Kazmaier, M.; Taefi, T.; Hettesheimer, T. Techno-economical and ecological potential of electrical scooters: A life cycle analysis. Eur. J. Transp. Infrastruct. Res. 2020, 20, 233-251. [CrossRef]

54. Calão, J.; Marrques, D.; Completo, A.; Coelho, M.C. A Life Cycle Thinking Approach Applied to Novel Micromobility Vehicle. In Proceedings of the 101st Transportation Research Board Annual Meeting, Washington, DC, USA, 9-13 January 2022. 
55. Coelho, M.C.; Almeida, D. Cycling Mobility-A Life Cycle Assessment Based Approach. Transp. Res. Procedia 2015, 10, 443-451. [CrossRef]

56. Agyekum, E.O.; Fortuin, K.; van der Harst, E. Environmental and social life cycle assessment of bamboo bicycle frames made in Ghana. J. Clean. Prod. 2017, 143, 1069-1080. [CrossRef]

57. Schelte, N.; Severengiz, S.; Schünemann, J.; Finke, S.; Bauer, O.; Metzen, M. Life Cycle Assessment on Electric Moped Scooter Sharing. Sustainability 2021, 13, 8297. [CrossRef]

58. Melo, S.; Baptista, P. Evaluating the impacts of using cargo cycles on urban logistics: Integrating traffic, environmental and operational boundaries. Eur. Transp. Res. Rev. 2017, 9, 30. [CrossRef]

59. Fraselle, J.; Limbourg, S.L.; Vidal, L. Cost and Environmental Impacts of a Mixed Fleet of Vehicles. Sustainability 2021, 13, 9413. [CrossRef]

60. Li, Z.; Madanu, S. Highway Project Level Life-Cycle Benefit/Cost Analysis under Certainty, Risk, and Uncertainty: Methodology with Case Study. J. Transp. Eng. 2009, 135, 516-526. [CrossRef]

61. Boadi, R.S.; Kennedy, A.A.; Couture, J. Risk-Based Planning in Transportation Asset Management: Critical Pitfalls. J. Transp. Eng. 2015, 141, 04014080. [CrossRef]

62. Karim, H.; Magnusson, R.; Natanaelsson, K. Life-Cycle Cost Analyses for Road Barriers. J. Transp. Eng. 2012, 138, 830-851. [CrossRef]

63. Chan, A.; Keoleian, G.; Gabler, E. Evaluation of Life-Cycle Cost Analysis Practices Used by the Michigan Department of Transportation. J. Transp. Eng. 2008, 134, 236-245. [CrossRef]

64. Shani, P.; Chau, S.; Swei, O. All roads lead to sustainability: Opportunities to reduce the life-cycle cost and global warming impact of U.S. roadways. Resour. Conserv. Recycl. 2021, 173, 105701. [CrossRef]

65. Kaewunruen, S.; Sresakoolchai, J.; Yu, S. Global Warming Potentials Due to Railway Tunnel Construction and Maintenance. Appl. Sci. 2020, 10, 6459. [CrossRef]

66. Yan, X.; He, J.; King, M.; Hang, W.; Zhou, B. Electric bicycle cost calculation models and analysis based on the social perspective in China. Environ. Sci. Pollut. Res. 2018, 25, 20193-20205. [CrossRef]

67. Kriit, H.K.; Williams, J.S.; Lindholm, L.; Forsberg, B.; Sommar, J.N. Health economic assessment of a scenario to promote bicycling as active transport in Stockholm, Sweden. BMJ Open 2019, 9, e030466. [CrossRef]

68. European Environment Agency. European Environment Agency the First and Last Mile-The Key to Sustainable Urban Transport. Available online: https:/ / www.eea.europa.eu/publications/the-first-and-last-mile (accessed on 27 March 2021).

69. Niiyama, R.; Sato, H.; Tsujimura, K.; Narumi, K.; Seong, Y.A.; Yamamura, R.; Kakehi, Y.; Kawahara, Y. poimo: Portable and Inflatable Mobility Devices Customizable for Personal Physical Characteristics. In Proceedings of the 33rd Annual ACM Symposium on User Interface Software and Technology, Virtual Event, USA, 20-23 October 2020; ACM: New York, NY, USA, 2020; pp. 912-923.

70. Bogdanski, R.; Cailliau, C.; Seidenkranz, M.; Bayer, M.; Reed, M. Development of a General Specification Sheet for Heavy-Duty Cargo Bikes. In Proceedings of the 2021 Sixteenth International Conference on Ecological Vehicles and Renewable Energies (EVER), Monte-Carlo, Monaco, 5-7 May 2021; pp. 1-11.

71. Kang, D.; Park, H.; Kwak, Y.; Kim, B.; Kim, S.; Kim, D.; Lee, S.; Kim, B.; Lee, H.S. Development of a Shared Indoor Smart Mobility Platform Based on Semi-Autonomous Driving. In Proceedings of the 2020 29th IEEE International Conference on Robot and Human Interactive Communication (RO-MAN), Naples, Italy, 31 August-4 September 2020; pp. 963-970.

72. Phannil, N.; Jettanasen, C. Design of a Personal Mobility Device for Elderly Users. J. Health Eng. 2021, 2021, 8817115. [CrossRef]

73. Fernandes, F.A.O.; de Sousa, R.A. Motorcycle helmets-A state of the art review. Accid. Anal. Prev. 2013, 56, 1-21. [CrossRef] [PubMed]

74. Bliven, E.; Rouhier, A.; Tsai, S.; Willinger, R.; Bourdet, N.; Deck, C.; Madey, S.M.; Bottlang, M. Evaluation of a novel bicycle helmet concept in oblique impact testing. Accid. Anal. Prev. 2019, 124, 58-65. [CrossRef] [PubMed]

75. Reuvers, R.; Over, E.A.B.; Suijkerbuijk, A.W.M.; Polder, J.J.; De Wit, G.A.; Van Gils, P.F. Cost-effectiveness of mandatory bicycle helmet use to prevent traumatic brain injuries and death. BMC Public Health 2020, 20, 413. [CrossRef]

76. Trivedi, T.K.; Liu, C.; Antonio, A.L.M.; Wheaton, N.; Kreger, V.; Yap, A.; Schriger, D.; Elmore, J.G. Injuries Associated with Standing Electric Scooter Use. JAMA Netw. Open 2019, 2, e187381. [CrossRef]

77. Liew, Y.K.; Wee, C.P.J.; Pek, J.H. New peril on our roads: A retrospective study of electric scooter-related injuries. Singap. Med. J. 2020, 61, 92-95. [CrossRef]

78. Papoutsi, S.; Martinolli, L.; Braun, C.T.; Exadaktylos, A.K. E-Bike Injuries: Experience from an Urban Emergency Department-A Retrospective Study from Switzerland. Emerg. Med. Int. 2014, 2014, 850236. [CrossRef]

79. Du, W.; Yang, J.; Powis, B.; Zheng, X.; Ozanne-Smith, J.; Bilston, L.; He, J.; Ma, T.; Wang, X.; Wu, M. Epidemiological profile of hospitalised injuries among electric bicycle riders admitted to a rural hospital in Suzhou: A cross-sectional study. Inj. Prev. 2013, 20, 128-133. [CrossRef]

80. Puzio, T.J.; Murphy, P.B.; Gazzetta, J.; Dineen, H.A.; Savage, S.A.; Streib, E.W.; Zarzaur, B.L. The electric scooter: A surging new mode of transportation that comes with risk to riders. Traffic Inj. Prev. 2020, 21, 175-178. [CrossRef]

81. Sanders, R.L.; Branion-Calles, M.; Nelson, T.A. To scoot or not to scoot: Findings from a recent survey about the benefits and barriers of using E-scooters for riders and non-riders. Transp. Res. Part A Policy Pract. 2020, 139, 217-227. [CrossRef] 
82. Hashimoto, N.; Tomita, K.; Matsumoto, O.; Boyali, A. Effects of Human Factors on Public Use of Standing-Type Personal Mobility Vehicle. J. Adv. Transp. 2020, 2020, 8876040. [CrossRef]

83. Yang, H.; Ma, Q.; Wang, Z.; Cai, Q.; Xie, K.; Yang, D. Safety of micro-mobility: Analysis of E-Scooter crashes by mining news reports. Accid. Anal. Prev. 2020, 143, 105608. [CrossRef] [PubMed]

84. Zagorskas, J.; Burinskienè, M. Challenges Caused by Increased Use of E-Powered Personal Mobility Vehicles in European Cities. Sustainability 2019, 12, 273. [CrossRef]

85. Sikka, N.; Vila, C.; Stratton, M.; Ghassemi, M.; Pourmand, A. Sharing the sidewalk: A case of E-scooter related pedestrian injury. Am. J. Emerg. Med. 2019, 37, 1807.e5-1807.e7. [CrossRef]

86. James, O.; Swiderski, J.I.; Hicks, J.; Teoman, D.; Buehler, R. Pedestrians and E-Scooters: An Initial Look at E-Scooter Parking and Perceptions by Riders and Non-Riders. Sustainability 2019, 11, 5591. [CrossRef]

87. Consumer Product Safety Commission. Safety Concerns Associated with Micromobility Products. 2020. Available online: https:/ / cpsc.gov /s3fs-public/Report-on-Micromobility-Products_FINAL-to-Commission.pdf?THHIorYXAZ.KiZnobh1 07.7.1N9nNCLo\%0A (accessed on 13 October 2021).

88. Hsieh, M.K.H.; Lai, M.C.; Sim, H.S.N.; Lim, X.; Fok, S.F.D.; Joethy, J.; Kong, T.Y.; Lim, G.J.S. Electric scooter battery detonation: A case series and review of literature. Ann. Burn. Fire Disasters 2021, 34, $264-276$.

89. Kong, L.; Li, C.; Jiang, J.; Pecht, M.G. Li-Ion Battery Fire Hazards and Safety Strategies. Energies 2018, 11, 2191. [CrossRef]

90. Vilaça, M.; Macedo, E.; Coelho, M.C. A Rare Event Modelling Approach to Assess Injury Severity Risk of Vulnerable Road Users. Safety 2019, 5, 29. [CrossRef]

91. Vilaça, M.; Macedo, E.; Tafidis, P.; Coelho, M.C. Multinomial logistic regression for prediction of vulnerable road users risk injuries based on spatial and temporal assessment. Int. J. Inj. Control Saf. Promot. 2019, 26, 379-390. [CrossRef] [PubMed]

92. Silva, P.B.; Andrade, M.; Ferreira, S. Machine learning applied to road safety modeling: A systematic literature review. J. Traffic Transp. Eng. 2020, 7, 775-790. [CrossRef]

93. Shirgaokar, M. Expanding Seniors' Mobility through Phone Apps: Potential Responses from the Private and Public Sectors. J. Plan. Educ. Res. 2018, 40, 405-415. [CrossRef]

94. Golub, A.; Satterfield, V.; Serritella, M.; Singh, J.; Phillips, S. Assessing the barriers to equity in smart mobility systems: A case study of Portland, Oregon. Case Stud. Transp. Policy 2019, 7, 689-697. [CrossRef]

95. Miralles, D.; Levigne, N.; Akos, D.M.; Blanch, J.; Lo, S. Android Raw GNSS Measurements as the New Anti-Spoofing and Anti-Jamming Solution. In Proceedings of the 31st International Technical Meeting of the Satellite Division of the Institute of Navigation, ION GNSS+ 2018, Miami, FL, USA, 24-28 September 2018; pp. 334-344.

96. Zhao, Q.; Zuo, C.; Pellegrino, G.; Lin, Z. Geo-locating Drivers: A Study of Sensitive Data Leakage in Ride-Hailing Services. In Proceedings of the 2019 Network and Distributed System Security Symposium, San Diego, CA, USA, 24-27 February 2019.

97. Benita, F. Human mobility behavior in COVID-19: A systematic literature review and bibliometric analysis. Sustain. Cities Soc. 2021, 70, 102916. [CrossRef]

98. Arimura, M.; Ha, T.V.; Okumura, K.; Asada, T. Changes in urban mobility in Sapporo city, Japan due to the COVID-19 emergency declarations. Transp. Res. Interdiscip. Perspect. 2020, 7, 100212. [CrossRef]

99. Monte, F. Mobility Zones. Econ. Lett. 2020, 194, 109425. [CrossRef]

100. Latinopoulos, C.; Patrier, A.; Sivakumar, A. Planning for e-scooter use in metropolitan cities: A case study for Paris. Transp. Res. Part D Transp. Environ. 2021, 100, 103037. [CrossRef]

101. Karlsson, I.; Mukhtar-Landgren, D.; Smith, G.; Koglin, T.; Kronsell, A.; Lund, E.; Sarasini, S.; Sochor, J. Development and implementation of Mobility-as-a-Service-A qualitative study of barriers and enabling factors. Transp. Res. Part A Policy Pract. 2019, 131, 283-295. [CrossRef]

102. Christoforou, Z.; de Bortoli, A.; Gioldasis, C.; Seidowsky, R. Who is using e-scooters and how? Evidence from Paris. Transp. Res. Part D Transp. Environ. 2021, 92, 102708. [CrossRef]

103. Gong, L.; Liu, X.; Wu, L.; Liu, Y. Inferring trip purposes and uncovering travel patterns from taxi trajectory data. Cartogr. Geogr. Inf. Sci. 2015, 43, 103-114. [CrossRef]

104. Zhang, Y.; Mi, Z. Environmental benefits of bike sharing: A big data-based analysis. Appl. Energy 2018, 220, 296-301. [CrossRef]

105. Zijlstra, T.; Durand, A.; Hoogendoorn-Lanser, S.; Harms, L. Early adopters of Mobility-as-a-Service in the Netherlands. Transp. Policy 2020, 97, 197-209. [CrossRef]

106. Shaheen, S.; Cohen, A.; Dowd, M.; Davis, R. A Framework for Integrating Transportation into Smart Cities; Mineta Transportation Institute Publications: San Jose, CA, USA, 2019; ISBN 0000000274555. Available online: https://scholarworks.sjsu.edu/mti_ publications / 275/ (accessed on 13 October 2021).

107. McKenzie, G. Urban mobility in the sharing economy: A spatiotemporal comparison of shared mobility services. Comput. Environ. Urban Syst. 2019, 79, 101418. [CrossRef]

108. Ciociola, A.; Cocca, M.; Giordano, D.; Vassio, L.; Mellia, M. E-Scooter Sharing: Leveraging Open Data for System Design. In Proceedings of the 2020 IEEE/ACM 24th International Symposium on Distributed Simulation and Real Time Applications (DS-RT), Prague, Czech Republic, 14-16 September 2020; pp. 1-8.

109. Barbour, W.; Wilbur, M.; Sandoval, R.; Dubey, A.; Work, D.B. Streaming computation algorithms for spatiotemporal micromobility service availability. In Proceedings of the 2020 IEEE Workshop on Design Automation for CPS and IoT (DESTION), Sydney, Australia, 21 April 2020; pp. 32-38. 
110. Günther, M.; Jacobsen, B.; Rehme, M.; Götze, U.; Krems, J.F. Understanding user attitudes and economic aspects in a corporate multimodal mobility system: Results from a field study in Germany. Eur. Transp. Res. Rev. 2020, 12, 64. [CrossRef]

111. Wortmann, C.; Syré, A.; Grahle, A.; Göhlich, D. Analysis of Electric Moped Scooter Sharing in Berlin: A Technical, Economic and Environmental Perspective. World Electr. Veh. J. 2021, 12, 96. [CrossRef]

112. Kelly, D.; Lupa, M.; de Araujo, M.P.; Casper, C. Asset Management of Vehicles: A Practical Application of the Logic Scoring of Preference Method of Optimizing Programmatic Investment Decisions in a Performance based System. Procedia Comput. Sci. 2014, 32, 681-690. [CrossRef]

113. Sinha, K.C.; Labi, S.; Agbelie, B.R.D.K. Transportation infrastructure asset management in the new millennium: Continuing issues, and emerging challenges and opportunities. Transp. A Transp. Sci. 2017, 13, 591-606. [CrossRef]

114. Butler, L.; Yigitcanlar, T.; Paz, A. Smart Urban Mobility Innovations: A Comprehensive Review and Evaluation. IEEE Access 2020, 8, 196034-196049. [CrossRef]

115. Ahmad, N.; Rafique, M.T.; Jamshaid, R. Design of Piezoelectricity Harvester using Footwear. In Proceedings of the 2019 IEEE 6th International Conference on Engineering Technologies and Applied Sciences (ICETAS), Kuala Lumpur, Malaysia, 20-21 December 2019; pp. 1-5.

116. Xia, H.; Chen, D.K.Y.; Zhu, X.; Shull, P.B. “Controlled Slip” Energy Harvesting While Walking. IEEE Trans. Neural Syst. Rehabil. Eng. 2019, 28, 437-443. [CrossRef] [PubMed]

117. Lowattanamart, W.; Suttisung, V.; Sintragoonchai, S.; Phanomchoeng, G.; Jintanawan, T. Feasibility on development of kineticenergy harvesting floors. IOP Conf. Ser. Earth Environ. Sci. 2020, 463, 012107. [CrossRef]

118. Jintanawan, T.; Phanomchoeng, G.; Suwankawin, S.; Kreepoke, P.; Chetchatree, P.; U-Viengchai, C. Design of Kinetic-Energy Harvesting Floors. Energies 2020, 13, 5419. [CrossRef]

119. Jettanasen, C.; Songsukthawan, P.; Ngaopitakkul, A. Development of Micro-Mobility Based on Piezoelectric Energy Harvesting for Smart City Applications. Sustainability 2020, 12, 2933. [CrossRef]

120. Giliberto, M.; Arena, F.; Pau, G. A fuzzy-based solution for optimized management of energy consumption in e-bikes. J. Wirel. Mob. Netw. Ubiquitous Comput. Dependable Appl. 2019, 10, 45-64. [CrossRef]

121. Akova, H.; Hulagu, S.; Celikoglu, H.B. Effects of energy consumption on cost optimal recharging station locations for e-scooters. In Proceedings of the 2021 7th International Conference on Models and Technologies for Intelligent Transportation Systems (MT-ITS), Heraklion, Greece, 16-17 June 2021; pp. 1-6.

122. Sanchez-Iborra, R.; Bernal-Escobedo, L.; Santa, J. Eco-Efficient Mobility in Smart City Scenarios. Sustainability 2020, $12,8443$. [CrossRef]

123. Liao, F.; Correia, G. Electric carsharing and micromobility: A literature review on their usage pattern, demand, and potential impacts. Int. J. Sustain. Transp. 2020, 1-30. [CrossRef]

124. Almannaa, M.H.; Ashqar, H.I.; Elhenawy, M.; Masoud, M.; Rakotonirainy, A.; Rakha, H. A comparative analysis of e-scooter and e-bike usage patterns: Findings from the City of Austin, TX. Int. J. Sustain. Transp. 2020, 15, 571-579. [CrossRef]

125. European Parliament. The Impact of Emerging Technologies on the Transport System. Available online: https://www.europarl. europa.eu/RegData/etudes/STUD/2020/652226/IPOL_STU(2020)652226_EN.pdf (accessed on 13 October 2021).

126. Comi, A.; Polimeni, A.; Nuzzolo, A. An Innovative Methodology for Micro-Mobility Network Planning. Transp. Res. Procedia 2022, 60, 20-27. [CrossRef]

127. Salmeron-Manzano, E.; Manzano-Agugliaro, F. The Electric Bicycle: Worldwide Research Trends. Energies 2018, 11, 1894. [CrossRef]

128. Field, C.; Jon, I. E-Scooters: A New Smart Mobility Option? The Case of Brisbane, Australia. Plan. Theory Pract. 2021, 22, 368-396. [CrossRef]

129. Pellow, M.A.; Ambrose, H.; Mulvaney, D.; Betita, R.; Shaw, S. Research gaps in environmental life cycle assessments of lithium ion batteries for grid-scale stationary energy storage systems: End-of-life options and other issues. Sustain. Mater. Technol. 2019, 23, e00120. [CrossRef]

130. Comi, A.; Savchenko, L. Last-mile delivering: Analysis of environment-friendly transport. Sustain. Cities Soc. $2021,74,103213$. [CrossRef]

131. Comi, A.; Delle Site, P.; Filippi, F.; Marcucci, E.; Nuzzolo, A. Differentiated regulation of urban freight traffic: Conceptual framework and examples from Italy. In Proceedings of the 13th International Conference of Hong Kong Society for Transportation Studies, Hong Kong, China, 13-15 December 2008; pp. 815-824.

132. Sierra, A.; Reinders, A. Designing innovative solutions for solar-powered electric mobility applications. Prog. Photovolt. Res. Appl. 2020, 29, 802-818. [CrossRef]

133. Shaheen, S.A.; Cohen, A.P. Shared Micromoblity Policy Toolkit: Docked and Dockless Bike and Scooter Sharing; UC Berkeley Transportation Sustainability Research Center: Berkeley, CA, USA, 2019; 34p. [CrossRef]

134. Martínez-Díaz, M.; Soriguera, F.; Pérez, I. Technology: A Necessary but Not Sufficient Condition for Future Personal Mobility. Sustainability 2018, 10, 4141. [CrossRef]

135. Che, M.; Lum, K.M.; Wong, Y.D. Users' attitudes on electric scooter riding speed on shared footpath: A virtual reality study. Int. J. Sustain. Transp. 2020, 15, 152-161. [CrossRef]

136. Esfandabadi, Z.S.; Ravina, M.; Diana, M.; Zanetti, M.C. Conceptualizing environmental effects of carsharing services: A system thinking approach. Sci. Total Environ. 2020, 745, 141169. [CrossRef] 
137. Saxe, S.; Kasraian, D. Rethinking environmental LCA life stages for transport infrastructure to facilitate holistic assessment. J. Ind. Ecol. 2020, 24, 1031-1046. [CrossRef]

138. Ozbay, K.; Jawad, D.; Parker, N.A.; Hussain, S. Life-Cycle Cost Analysis: State of the Practice Versus State of the Art. Transp. Res. Rec. J. Transp. Res. Board 2004, 1864, 62-70. [CrossRef] 